UNIVERSITY OF VAASA

FACULTY OF TECHNOLOGY

INDUSTRIAL MANAGEMENT

\title{
Javad Rouzafzoon \\ DEVELOPING SERVICE SUPPLY CHAINS BY USING AGENT BASED SIMULATION
}

\author{
Master's Thesis in \\ Industrial Management
}

(Economics and Business Administration)

VAASA 2016 
UNIVERSITY OF VAASA

Faculty of Technology

Author:

Topic of the Master's Thesis:

Instructor:

Degree:

Major Subject:

Year of Entering the University:

Year of Completing the Master's Thesis:
Javad Rouzafzoon

Developing Service Supply Chains

By Using Agent Based Simulation

Prof. Petri Helo

Master of Science in Economics and

Business Administration

Industrial Management

2013

2016

Pages: 79

\begin{abstract}
:
The Master thesis present a novel approach to model a service supply chain with agent based simulation. Also, the case study of thesis is related to healthcare services and research problem includes facility location of healthcare centers in Vaasa region by considering the demand, resource units and service quality. Geographical information system is utilized for locating population, agent based simulation for patients and their illness status probability, and discrete event simulation for healthcare services modelling. Health centers are located on predefined sites based on managers' preference, then each patient based on the distance to health centers, move to the nearest point for receiving the healthcare services. For evaluating cost and services condition, various key performance indicators have defined in the modelling such as Number of patient in queue, patients waiting time, resource utilization, and number of patients ratio yielded by different of inflow and outflow. Healthcare managers would be able to experiment different scenarios based on changing number of resource units or location of healthcare centers, and subsequently evaluate the results without necessity of implementation in real life.
\end{abstract}

KEYWORDS: Service supply chain, Agent-based simulation, Facility location, GIS, Healthcare 


\section{TABLE OF CONTENTS}

1.1 Operation research in healthcare $\quad 8$

1.2. Worldwide health issues for operation management 11

2. LITERATURE REVIEW 16

2.1. Agent-based simulation 16

2.2. Facility location 23

2.3. Patient flow 36

3. RESEARCH METHOD 50

4. METHOD AND MATERIALS 51

4.1. Agent Based simulation $\quad 51$

4.2. Patient flow simulation $\quad 52$

4.3. Geographical information system 53

4.4.Key performance indicators $\quad 55$

5. DESIGN OF EXPERIMENT 60

6. DATA AND CHART ANALYZING 63

7. RESULT AND DISCUSSION 68 
8. LIST OF REFERENCES 


\section{LIST OF FIGURES}

$\begin{array}{lc}\text { Figure 2.Conceptual framework of triple-diffusion model. } & 18\end{array}$

Figure 3. Flow chart of interactions between the three diffusion processes. 20

Figure 4. Patient States and Transition. $\quad 52$

Figure 5. Patient Flow. $\quad 53$

Figure 6. GIS map with regions. $\quad 55$

Figure 7. Number of Patient in Queue. 56

Figure 8. Lengths of Stay. $\quad 57$

$\begin{array}{ll}\text { Figure 9. Resource Utilization. } & 58\end{array}$

Figure 10. Number of patients ratio yielded by different of inflow and outflow. $\quad 59$

$\begin{array}{ll}\text { Figure 11. Black box diagram. } & 60\end{array}$

Figure 12. Maximum patient's lengths of stay per various number of healthcare centers. 63

Figure 13. Average patient's lengths of stay per various number of healthcare centers. 64

Figure 14. Number of Patients in Queue per each scenario. 65

Figure 15. Resource Utilization per each scenario. 66 


\section{LIST OF TABLES}

page

Table 1. Simulation results with 20 healthcare centers.

61

Table 2. Result of simulation with 15 healthcare centers.

62

Table 3. Simulation results with 10 healthcare centers.

62

Table 4. Simulation information for 5 healthcare centers.

62 


\section{INTRODUCTION}

Healthcare systems contains between 8 to 15 percent in most developed countries economy. It can be considered as one of the largest sectors in any state, even bigger than IT, Education, Telecommunication, Tourisms, and Agriculture. (Walshe \& Smith 2011.)

One from ten employers are involved in healthcare sector in most of countries as nurses, doctors, engineers, clerk, administrators, cook, cleaner, therapists, finance controllers and managers. This proves that everyone has a direct relationship or knows someone who is connected to healthcare section. Also, almost everyone has a perspective regarding their local healthcare system. In addition, Healthcare workforce can be political dominant group with possessing significant influence on public opinion. (Walshe et al. 2011.)

Progress of Healthcare systems has been combined with development of society and communities. In many eras, there were religious associations, donations, voluntary institutions, commerce organizations and regional communities played major role in establishing and evolving health services. Even these days, people feel connected to health services and are even willing to finance activities which support and protect healthcare workforce. Governments also due to its importance in people's view try to improve and reorganize health services for better serviceability and efficiency, but sometime when

people's emotion and government proposals about changing health services are in conflict, what people request matters, not what works. (Walshe et al. 2011.)

For many politicians health policy and healthcare system is like two edged sword. On the one hand, when it is performing well, it would create opportunity for politicians to shine in front of electorate. On the other hand, it would jeopardize future politician election if there is not proper healthcare financial and service provision because people consider officials as responsible for individuals. Politicians may also obtain political benefits by presenting a new facility or improving current service. (Walshe et al. 2011.) 
Furthermore, press including online media, TV, radio, focuses extremely on healthcare matters. Actually, healthcare is considered as indefinite source of debates, stories and arguments. Healthcare issues can cover several pages in national dailies and reflected also again on TV news. Even at local level, newspapers have health and clinic related topics in every issue. (Walshe et al. 2011.)

Healthcare organizations can utilize the media eagerness in health context in order to communicate and broadcast health services to public, but if there are defaults in healthcare system, the press is considered then as threat. (Walshe et al. 2011.)

Actually, performance and actions of healthcare organizations is extremely evident and scrutinized due to they exist in chaotic political and social environment. Healthcare leadership and management takes place in this context and its results depends on performance and process of Healthcare management. (Walshe et al. 2011.)

Healthcare services are confronted by four challenging and inevitable social trends in developed countries:

- The population shift

- The pace of emerging technologies and inventions

- Shifting user and consumer expectations

- Growing cost due to world economic recession. (Walshe et al. 2011.)

The demographic challenge is due to today life standards, people live longer, number of old and very old people is increasing rapidly, and these people use extremely healthcare services. With advances in healthcare systems, people might live longer, but within last years of life trend in which they have more frequent and diverse health issues, their health expenses are higher. Growing occurrences of chronic diseases in wider populations can be another aspect of the demographic challenge. Based on World Health organization, smoking, physical 
inactivity, and invalid regimes are major effective factors of this incident. (Walshe et al. 2011.)

The second challenge is related to the first one as it increases the potential of controlling chronic diseases and living longer. Investigating and discovering new approaches in pharmacological, surgery, diagnostics and other areas influence in treating and managing diseases. In other word, innovations include finding new therapies which are more effective and treatments have not existed before for some diseases. Earlier fatal conditions can be treated and novel methods by which progress of diseases can be monitored or slowed down are more accessible. (Walshe et al. 2011.)

The third challenge is connected with second one. People need more health services than their parents had. Receiving medical prescription by service provider is not what people just request; people expect the health providers to play a part in every decision in their life which affects their health.(Walshe et al. 2011.)

All three mentioned factors influence on fourth item; increasing cost. Each of them has its own level of pressure on healthcare funding, but this pressure is more severe for countries confronting with global economic recession. Approximately, in other areas of economy, productivity is increasing and costs are diminishing due to competition and innovations. Consumer goods, cars, computers, foods and etc. are producing cheaper, better and faster, but still in healthcare costs are high and rising with demand for services. With world global economic recession, reducing resources for healthcare services has become an acute challenge for many countries. Therefore, Managers must focus on how to assign resources and defining priorities in services.(Walshe et al. 2011.)

\subsection{Operation research in healthcare}

The research gap in operation and process control problems was presented to international healthcare seminar at Alma-Atena 1987. Since that conference, WHO, world Health Organization has announced with successive reports, the necessity for researches to improve 
the health services. Particularly, in health delivery which is major challenge of healthcare systems.(Royston 2011.)

Operation research has played a major role for enhancing organizations and supplying services in various human related subjects. Operation management first time was applied by Britain air force, World War II. By applying operation research concepts, fighters command efficiency was doubled by designing unified information system and control system. Since that time, its application became common, for example, restructuring the overnight delivery for the largest logistic company led to saving yearly 270 million US dollars, and global vehicle company increased the efficiency and saved 250 million US dollar annually. (Royston 2011.)

Rarely, operational management and research has been used in health system, particularly in global healthcare. For instance, only 5 percent of each funding is assigned to monitoring, assessment and operations research by the International support to stop diseases such as Malaria, AIDS, and TB. Based on last surveys, only $3 \%$ of budget is considered for operation research in projects and in reality, less than this amount is expended. (Korenromp E 2007.)

Despite neglecting the role of operational research by global health, there has been some notable works in healthcare operational research. For example, US Agency for global development lunched 32 country program on healthcare in operation research by 1981; several years of operation research efforts for controlling tuberculosis; Applying operation research for HIV/AIDS. (Royston 2011.)

Managers apply wide range of scientific tools for healthcare operation research problems; they utilize numerical methods, designing qualitative problem and finding solutions methods. Tools demonstrated on top left corner of Figure.1 from Pidd (2003) are mainly qualitative research tools applied with group of individuals who participate in meetings. On the bottom of right corner, mostly numerical studies tools used with individual analyst in desk-based work. For instance, behavioral simulation includes how stakeholders of a company react to organization change or problem situation in order to estimate the outcomes of their actions. 
Computer Modelling is used in agent based and discrete event simulation for exploring about major system element (Agents), its interaction and results from system modification. (Royston 2011.)

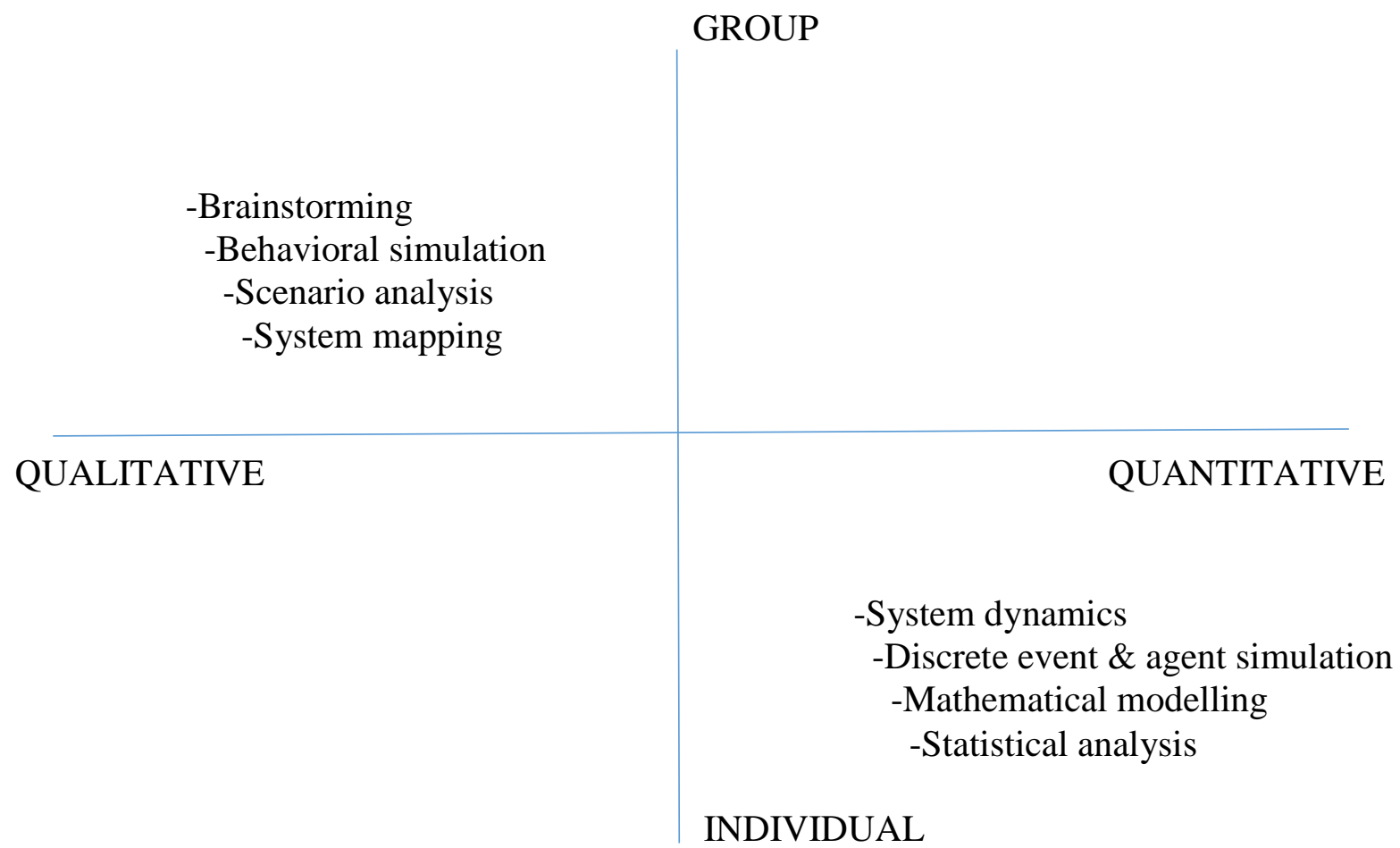

Figure 1. Research tools.

At initial stages of research, qualitative methods are likely to be used or when time and data are partially available for research and tools such as root cause analysis and system mapping can be useful. Also, quantitative tools can be applied even with limited data because the research results usually are based on logic and structure of situation than exact value of parameters. Modeling should not be discarded from research. Modelling and other tools can be significant combination in a way that a tool restriction can be compensated by other tools. For example, investigating about system outputs by changing the parameters can take several years, while with simulation and modelling this constraint does not exit. (Royston 2011.) 


\subsection{Worldwide health issues for operation management}

In this section, key challenges of global healthcare systems and role of operation research and management will be mentioned.

\section{Identifying problems:}

Operation research can contribute in systematic identifying problems and even exploring solutions. Approaches such as Strategic choice approach or system creativity method are applicable especially in low resource situation.(Royston 2011.)

New approaches also play an important role in healthcare management, because health policy and strategies should be designed in a way that to deal with present and upcoming challenges. Therefore, scenario analysis and future approaches are more preferable than methods such as traditional forecasting methods. (Royston 2011.)

\section{Choosing Intervention:}

Selecting proper interventions is clearly critical step. Researchers must be familiar with evaluating methods for interventions and factors such as effectiveness, cost and safety should be considered. Combination of modelling and pilot research can be executed to improve and assess the interventions before implementing them in large scale.(Royston 2011.)

\section{Introducing New Interventions:}

One of the main global health challenges is Innovation. For instance, telemedicine has been increasingly implementing in many countries with spread of global mobile networks, but in developing countries, delivery and design of service can be improved by operation research methods.(Royston 2011.)

\section{Scaling up:}


If the small scale projects are supposed to be implemented for large scale, it needs to be modified considerably. For instance, what are the consequences of treating or vaccinating whole country? In this up scaling, factors such as predicting future demands, specifying location and size of facilities, and employee level should be defined. In fact, locating facilities and services, handling pharmaceutical supply chain and administrating health care staff can be conducted by simulation modelling. (Royston 2011.)

\section{Integrating into health systems:}

Progress and success in healthcare systems are derived from collaborative interactions between individuals, societies, and national authorities. Actually, concentration on how to proceed involvements in complicated behavioral milieu, and exploring of how complex systems can capture changes positively, is required. In this context, operational management concepts can be applied, for instance, modelling HIV diffusion in rural areas by agent based simulation method. (Alam SJ 2008.)

\section{Evaluation:}

Assessment and measurement of projects performance is one of the main challenges of global health systems. For instance, evaluation on United Nations Children Fund (UNICEF) demonstrated improving in child survivals and projects completion. Also, in this research, it is stated that "Evaluation must now become the top priority in global health".(Bryce J 2010.)

Evaluation tools can be Standard control trial approaches which are usually practical and suitable, but sometimes methods such as system oriented modelling are required. Also, decision tree modelling can provide information regarding efficiency of operations and procedure costs.(Royston 2011.)

Gaining significant promotion in healthcare requires major improvements such as progresses in enquiries and analyzing institutions and health care distribution. (Royston 2011.) 
Following factors will diminish the implementation issues in healthcare. Also, stronger connection with organizations which are active in healthcare environment improvement could be useful. Success factors are mentioned in three following sections. (Royston 2011.)

People:

- Build a connection between service staff and educational personnel in a society, staff with service area can focus on research priorities.

- Having various and proper combination of references from academies, research institutions, non-governmental institutions, public and private segments, connected to regional managers and academic individuals.

- Applying the expertise of public and also patients can be involved in arranging, planning and carrying out researches.

- Inspiring information accumulators by presenting data usage to them

- Stress on transferring analyzing abilities to regional scholars. (Royston 2011.)

\section{Methods:}

- Utilizing system analysis in order to discover the highest significant issues.

- Using efficient investigation in order to find different potential solutions.

- Modified approaches to balance (local, domestic, global).

- Defining management techniques which can be applied in health regularly; also tools require management scientists to adjust for each context.

- Streamline the original decision models in a way that expert individuals are not required to employ them.

- Discarding methods which require extreme local data and communication technology.

- Utilizing more participative methods such as system mapping, cause effect analysis, etc. which involve people and patients. 
- Decrease emphasizing on researches which is performed with one single sample group with providing more for ongoing investigations. (Royston 2011.)

\section{Communication:}

- Expanding communication and public relation skills for applying the research outcomes into the practice.

- Considering other potentials in order to establish the results to the other countries.

- Presenting the research to be issued in peer-review essay. (Royston 2011.)

In order to present services to patients, authorities require data; for example in UK, there are two types of organizations:

i) Purchasing authorities who define service requirements of the population and how to fulfill it within the specified budget.

ii) Service providers who must identify needed service types and cost them competitively. (Huw T.O. \& Ruth 1993.)

Authorities need information regarding patients' activity and following extent of healthcare services. In order to apply these information in pricing and budgeting, authorities require models to forecast the future service needs and assess resource usage by patients. (Huw T.O. et al. 1993.)

Institution of health has defined six purposes for raising quality of health delivery. It is recommended that health organizations should struggle for becoming secure, active, patientfocused, prompt, productive, and stable. (IOM 2001.)

Rouse \& Cortese (2010) mentioned that qualifoed and economical healthcare system are the most sophisticated, steady and urgent issues that US politicians, people and businesses encountering.CMS (2010) also presented statistics which demonstrated health cost is on extreme rise for patients and as GDP percentage. Reagrding healthcare quality, exemplified health system issues derived from improper care . 
Carrying out research in healthcare has become critical in order to improve the health system performance. There has been goals such as minimizing healthcare expense, rising human resource utilization, improving qaulity by presenting effective fiagnostic systems,managing of rising sick people number efficiently within restricted time interval, providing various healthcare equipments in one site, enhancing total health service quality whithin restricted and pre-specified time and budget. Cost rising of healthcare systems including operation, maintanance and healthcare expence because of utilizing updated technologies, equipments and methods have added more limitations to health system problems. (Brailsford \& Vissers 2011; Brandeau, Sainfort, \& Pierskalla 2004; Rais \& Viana 2011.)

From various section in healthcare, hospitals are the most integrated part which include different sub units such as emergency department, operation theatre, inpatient section, intensive care unit,diagnostic services. Also the efficiency of hospitals services depends on each unit performance and each unit has its own issues and limitations. For measuring healthcare system performance several indicators have introduced such as waiting time, lengthof stay, utilization of operating rooms and bed in ICU.(Bhattacharjee \& Ray 2014.) 


\section{LITERATURE REVIEW}

\subsection{Agent-based simulation}

Regarding simulation application in healthcare industry, Royston (2007) found more than 3500 Google Scholar subjects related to Health Simulation between 2000 and 2004 which is approximately three time growth in previous three years.

Taboada, Cabrera, Iglesias, Epelde, \& Luque (2011) performed a simulation modelling for Emergency department (ED) of hospital.

$\mathrm{ED}$ is one of the most critical hospital section for which huge amount of budget is considered due to variation in demands based on time, week days and years season, resource planning is complicated and demanding. Simulation steps are followed by completion of cycles including system analysis, model layout, simulator operation, simulator performance and outcomes examination, simulator authentication. (Macal \& North 2006.)

For simulation process, author considered two different type of agent; dynamic and inactive. Dynamic agents include all entities engaged in ED sector such as Doctors, Patients, Nurses, and administration staff, but inactive agents represents services and other reactive structure like IT infrastructure and services needed for performing medical experiments and tests. Also, in this research, physical environment is included in modelling. Different areas such as waiting room, triage box, administration and treatment are considered and agent interact or even travel in these places. (Taboada et al. 2011.)

Simulation is performed in Netlogo software and it is possible to discover connections in micro level, individuals' behavior, and macro level with patterns created by agents' interaction. (Taboada et al. 2011.) 
Simulation is implemented initially by varying four different probability of patients arrival; 20, 40, 60 and 80 percent. Only with 20 and 40 percent, patients received the health service without staying in queue. (Taboada et al. 2011.)

Second scenario was performed based on keeping patient arrival and number of staff static and changing the level of ED personnel experience to evaluate the throughput of system. From the simulation outcomes, it was concluded that increasing the experience in triage nurses or doctors should be planned. (Taboada et al. 2011.)

Third scenario includes altering number of ED staff to estimate the health system throughput. Author concluded that system is more sensitive to rise in professional staff than nurses in reducing the patient waiting time. (Taboada et al. 2011.)

Mao (2014) investigated on the triple diffusion of diseases. Based on Funk, Vincent, \& Jansen (2013) Epidemics includes three parts; contagious diseases, data and information exist about the diseases, and how people react in preventive manner to diseases. Funk et al. (2013) stated disease can be scattered by person to person contact, information spread by communicational links, and preventive actions can be circulated by social contagion such as learning by observation, and this component synergy builds the epidemics dimensions.

Contact between people form a network structure by which interactions and diffusion are possible. Modelling was performed through designing of three different layers. Diseases transfer through the direct contact between individuals (middle layer), disease control strategies such as isolation, case treatment and vaccinating program influence on extent of disease diffusion. Also, diseases circulation causes "word-of-mouth" discussion which spreads information regarding diseases and preventive behavior, (upper level). Diseases uprising prompt the mass media such as Radio, TV, News Paper to broadcast the relevant information, therefore, it increases information circulation. On the lower level, when individuals receive disease information, they would decide whether to take preventive strategies or not. This act affects their network neighbor to adopt which is widely called as "social contagion" effects. Dissemination of preventive behavioral strategies accelerates 
information circulation and reduces diseases spread. Also, health institutions can launch behavioral interventions, as an external element, in order to develop preventive behavior; such as educational, incentive and role based strategies. These three factors interact with each other during the epidemics and they build Positive or negative cycle of feedback which is demonstrated by arrows in Figure2. The triple-diffusion process, influenced also by external factors, defines the dimensions of epidemics. (Mao 2014.)



Figure 2.Conceptual framework of triple-diffusion model.

Modelling is performed through the agent based method which has been increasingly used since last decade in epidemics. Contrary to traditional population simulation, in agent based modelling, each individuals is a modelling unit along with specifications and factors which changes its state. (Burke, Epstein, Cummings, Parker, Cline, Singa \& Chakravarty 2006; Huang, Sun, Hsieh, \& Lin 2004.)

In order to provide a contact network, individuals are considered as nodes which are connected through their relationship to one another on daily basis. Connections between individuals are performed three times per day and in four different kinds of location. Time periods include during day in workplaces, nights at home and leisure time at service places and house neighborhood. Individuals move to these four places during three time intervals to fulfill their daily life necessities, therefore, they are in contact with various groups of people and are in exposure to infectious individuals. These links builds contact network of 
population. Also, author stated that two types of population contacts are considered based on contact duration and closeness. Close contact type which takes place with family at home, workplace with colleagues and household neighborhood with friends. Disease transmission happens when individuals are in contact with infectious people within the adequate time. The second type takes place occasionally at service places with consumers and clerks. Rate of transmission is lower due to less number of individuals contact and shorter time exposure with infected people. (Mao 2014.)

Diseases transmission is modelled based on classical method of SIR; Susceptible, Infectious, and Recovered and each individual cross through these steps. First, if susceptible person is contacted to infected people and receive the disease agent, that individual' state changes to Latent. Illness progress inside the person's body, and a time period, state changes to Infectious. Infectious individuals can transmit the diseases to susceptible people within the contact networks. Infected people may display the disease symptoms; Symptomatic or not; Asymptomatic. For both states, they can transmit the disease, but they are in unaware condition as Asymptotic. After passing time period of infectious, Recovered state is triggered, and individuals in this stage, become immune against the disease during the epidemics. (Mao 2014.)

Also events which affect disease spread are considered; symptoms manifestation which encourage others to discuss about disease and act with preventive behavior. Therefore, probability of disease transition reduces when people adopt preventive behavior. Actually, Author focuses on three factors in defining probability of disease diffusion; degree of contact closeness, probability of infection transmission based on different age groups such as kids, adults and old people, and adoption of preventive behavior efficiency. (Mao 2014.)

Individuals are initially Unaware, but they can be switched to Informed state. Information circulation implemented based on two methods; Word of Mouth discussion which scatters information through network ties and Mass Media which spreads information to whole population. (Mao 2014.) 


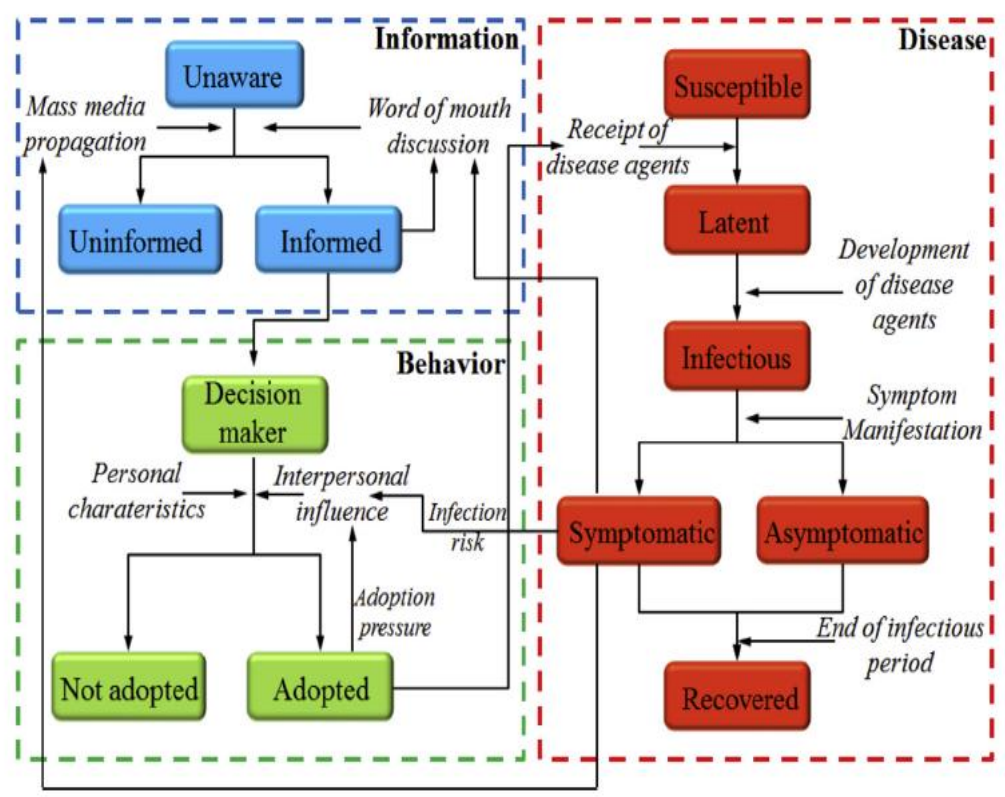

Figure 3. Flow chart of interactions between the three diffusion processes.

Mao (2014) conducted the research in Greater Buffalo Metropolitan Area, NY, USA, with 985,001 inhabitants, and each individual includes 6 type of attributes; "networks, spatiotemporal, infection, adoption, and information”.

Also geographical map of Buffalo Metropolitan Area was utilized to demonstrate the diffusion of disease during the simulation time period. He also compared the simulation results with two historical source of information; New York State Department of Health weekly laboratory report which was confirmed by specimens in 2004-2005 and weekly data from Google Flue trends of the research area. Interestingly, results fit very well with the historical data; day 50 rising epidemics rate, day 75 top of infectious rate and day 100 infectious is in decline. This model can be used in disease control policies, mass media campaign and human incentive strategies.(Mao 2014.)

Agent based simulation have been utilized in various fields in researches. For instance, Chu, You, Wassick, \& Agarwal (2015) applied agent based simulation (AB) for multi-echelon inventory optimization problem and in the simulation modelling and optimization problem, 
Monte Carlo technique, cutting plane algorithms, experimental design method and statistical hypothesis experiments are combined.

Chu et al. (2015) mentioned there are different types of inventory models, but distribution inventory system is considered in research (the tree structure), and the network is constituted of plant, distributers and distribution centers.

Sequential optimization and modelling method because one by one stage optimization lead to inaccurate results and also there are various unknown parameters in inventory systems due to utilizing inventories as buffers against demand violation and lead time fluctuations. Therefore, agent based modelling with four agent type is applied in his research; Facility agent which monitor and replenish inventory, Order agent which save data such as demand, sender, receiver, and status, Shipment agent which record data such as shipment quantity, shipping time, sender and receiver, Customer agent which create orders based on related probability. (Chu et al. 2015.)

Agent based simulation is applied when there are various participants in system who acts independently, interact with each other, react to system changes, and their total activity is nonlinear and not derived from summation of each individuals' behavior. (Ge, Gray, \& Nolan 2015.)

Vriend (2000) mentioned two forms of learning exist for agents; singular and population levels. In singular level, agents learn from its own experience, but in population level, it learns from other agents.

Ge et al. (2015) in his research, modeled the farmers' behavior by agent based simulation. Actually, farmers are smart agents who can perform the Thought experiments. They look over their neighborhood and collect the information in order to behave based on that data for next period. Ge et al. (2015) also considered risk effort factor for farmers. If a delivery is misrepresented by farmers, a punishment will be charged to farmers. Penalty system leads to motivation toward increasing the efforts for improved delivery (Ge et al. 2015). 
Agent interaction also is modeled by defining physical distance between farmers which based on it, farmers would exchange the information. If a farmer within specified distance has been tested by a system, then the neighborhood farmers would act more carefully in deliveries, on the other hand, if a farmer has not been checked for a time period, then the region farmers would reduce their efforts in accurate and valid deliveries. (Ge et al. 2015.)

Lancioni (2000) stated that the critical section in supply chain management is inventory control which 50 percent of cost is derived from it. Mortazavi, Arshadi Khamseh, \& Azimi (2015) mentioned that supply chain ordering management, SCOM, has direct link to inventory control.

Four echelon supply chain consist of distributer, retailer, manufacturer and supplier was chosen for the simulation modelling. Inventory quantity is assessed on weekly period and, then orders are placed. Retailors are allowed to perform the policy of partial demand satisfaction in modelling, and orders are sent to distributer each week. (Mortazavi et al. 2015.)

For manufacturing agent, modelling is more complicated, because it receives the orders weekly and orders are fulfilled or backordered. Manufacturing agent consists of two types of raw and finished products, and also it consists of producing operation which transfer the raw materials to finished products. Therefore, there exist two types of lead time, manufacturing and transportation. Supplier is also modeled as an agent and procurement time is considered for it. (Mortazavi et al. 2015.)

Mortazavi et al. (2015) also defined penalty cost related to backordering and other cost such as transportation, setup, manufacturing and holding in the modeling.

Mortazavi et al. (2015) also applied reinforcement learning (RL) method which is for instructing the agents to learn how to distinguish situations and select the related actions in order to maximize the numerical reward signals to reach an optimum strategy. 
The most challenging part of RL is to define a routine for action selection in learning stage. Agents have to choose between using the knowledge and select the best action or discover various actions to assess the new opportunities for agent policy improvements. (Mortazavi et al. 2015.)

Mortazavi et al. (2015) defined two types of probabilities; Exploitation which agent choose action based on current knowledge about situation and Exploration which agents select an action arbitrarily.

\subsection{Facility location}

Application of Facility Location Problems (FLP) covers various areas, for example location of distribution center in supply chain, warehouse location for a commodity producer, sporting facility for a city planner and even database location in computer networks.(Boloori Arabani \& Farahani 2012.)

FLP problems can be distinguished based on two factors; Time and Space. Space refers to area in which facilities are located and time indicates time of facility establishment. FLP factors can be also explained according to discrete and continuous features. For example, facilities with discrete aspect can be situated only on some points in planning area while in continuous space, they can be sited on any spot inside the planning area. Furthermore, discrete time indicates building additional sites or altering the existing sites is possible only on pre-specified time points while in continuous time, this kind of restrictions does not exist.(Boloori Arabani et al. 2012.)

In FLP problems, space factor is considered more critical than time issue, therefore in Static Facility Location Problems, SFLP, space factor is considered, but in Dynamic Facility Location Problems, DFLP, time element is focused. (Boloori Arabani et al. 2012.)

Boloori Arabani et al. (2012) explained the Continuous Facility Locating Problems, CFLP, as a subset of SFLP concepts. In these problems, models are affected by two major elements: first in continuous space, there is possibility to locate the facilities on every spot of the 
planning area; second, based on measurement indices, distance between facilities and customers are calculated. ReVelle, Eiselt, \& Daskin (2008) mentioned examples of setting video cameras and pollution censors locations for screening the environment as utilization of these models.

There exist three types of CFLP problems;

Single Facility Location Problems:

Boloori Arabani et al. (2012) mentioned in this category, the location is placed on a point which its distance to other facilities are minimized, and distance can be defined based on Euclidean or Manhattan methods. Wesolowsky (1973) introduced the first and elementary version of these problems with an objective function which total cost is minimized. In a research by Diaz-Banez, Mesa, \& Schobel (2004) more updated versions of these models such as " half-line facilities, hyper planes and spheres, polygonal curves, the location of single line and multiple lines in the plane are collected."

\section{Multi Facility Location Problems:}

Boloori Arabani et al. (2012) stated MUFLP are similar to SIFLP problems due to fact that in SIFLP, optimized location of only one new facility is considered while in MUFLP is concerned with location of several additional sites. Daneshzand \& Shoeleh (2009) defined a MUFLP model in which weights for distances between new locations are also considered.

\section{Facility location-allocation problem:}

In these models, two objectives are searched as optimized solution, location of facilities and allocating them to clients in order to respond to demands. ReVelle \& Swain (1970) introduced the first version of this model in which total cost derived from customers allocation to facilities is minimized.

The other kinds of these models can be with capacity restrictions of facility allocation to clients such as cost, time and etc. Also, there are multi commodity facility allocation 
problems in which several products instead of single commodity is considered. (Boloori Arabani et al. 2012.)

\section{Discrete Facility Location Problems:}

Two separate category of demand and location exists in DFLP problems. Since demands are usually assumed occurs within specific geographical regions, this parameter is considered as discrete one. "Quadratic assignment problem ( $Q A P)$ and plant location problem (PLP)" are considered as major problems of DFLP. QAP problems resemble to assignment problems in which group of individuals are assigned to jobs, but in FLP context, facilities are assigned to customers. (Boloori Arabani et al. 2012.)

In integer type of DFLP model, cost of assigning a facility to customer is minimized and main constraints include assigning only one facility to one customer, in another words, only one customer or facility can be designated to one others. (Koopmans \& Beckmann 1975.)

Plant Location problems consists of collection of facilities which each of them can be warehouse, production, distribution facility and it is applied in many different areas. Also, it is usually considered as problems without capacity restrictions. (Boloori Arabani et al. 2012.)

Network Facility Location Problem:

Network facility location problem is combined with a system feature composed of Nods and connections based on that demand can occur. There are five classifications of these problems which are explained as following. (Boloori Arabani et al. 2012.)

\section{Median Problems:}

$\mathrm{P}$ median is extended version of 1 median problem which looks for the most proper locations for $\mathrm{P}$ facilities and also specify facilities which fulfill the demand node as the weighted interval cumulative for each request node to its closest facilities is minimized. Also, different kinds of this problem include with or without capacities constraints.(Boloori Arabani et al. 2012.) 


\section{Covering problems:}

Toregas, Swain, ReVelle, \& Bergman (1971) introduced initially this type of problem, and in covering problems each client can be served by every facility if only distance between facility and customer is not more than allowable distance which is called coverage distance.

\section{Center Problems:}

Compared to covering problems, center models seek for potential location on the planning area which is able to respond to all demand while facilities should maintain minimum distance to demands points. Also, vertex p-center problem is considered as one of the most important type of these problems in which facilities are only allowed to be placed on network nodes. (Boloori Arabani et al. 2012.)

\section{Hub Location Problems:}

O'Kelly (1987) published the initial type of this problem in which objective function is based on minimization of total cost. O'Kelly (1987) also stated that factors such a discount, flow and transportation cost between nodes are taken into account.

\section{Hierarchical Location Problems:}

In HILP problems, there exist numerous classified facilities inside a distribution system context and upper hierarchy layer of facilities can choose the facility locations independently from lower layer. It should be taken into account that in these kinds of problems, handling and transshipment costs are calculated based on proportional to the products quantity transported. (Boloori Arabani et al. 2012.)

Also, Sahin \& Sural (2007) mentioned the primary version of HILP problem with one flow and two hierarchical layer.

In previous section, SFLP problem were discussed and in the following part Dynamic Facility Location Problems (DFLP) will be described. 
In DFLP problems, two major factors influence on selecting the appropriate facility location; 1) deciding on trade-off based on expenditure derived from establishing a another facility or improving the existing one, 2) closing or opening time of facility according to planning perspective. (Boloori Arabani et al. 2012.)

There exist second view regarding categorizing DFLP problems. In Explicit Dynamic problems, facilities will be opened or closed at pre-determined time period and sites while in Implicit Dynamic models, facilities begins working at specific time and stay open during the planned time period. (Boloori Arabani et al. 2012.)

DFLP problems also consist of different types which are categorized as following section:

\section{Dynamic deterministic facility location problem:}

Static models which searches for optimized location based on cost, there are situations in which other effective parameters such as ecological factors, state residents, demand pattern, market trends, etc. are being varied over different time intervals. Actually, these changes occur in real world issues and there is necessity to adjust, change, and relocate the facilities. Therefore, there is a gap to be filled by dynamic models for these kind problems. (Boloori Arabani et al. 2012.)

Wesolowsky (1973) stated that mentioned there is possibility to shift single facility location problems to Dynamic deterministic Problems. In these problems, optimized result for every P time period instead of single solution for whole time period is examined.

\section{Facility location-relocation problem:}

Due to interaction of elements such as clients, suppliers, government regulations, business atmosphere, parameters for locating the facilities would change, and consequently, companies consider the relocation of facilities or revising the current ones. (Boloori Arabani et al. 2012.) 
Three factors should be taken into account regarding facility relocation; number, time and cost of relocation. Facilities can be relocated according to discrete or continuous time. For discrete time, Facilities sites are changed on explicit, pre specified and discrete point of time while in continuous time periods, there are no predetermined time points and changes can be performed at any time during planning period. (Boloori Arabani et al. 2012.)

Also, concerning the relocation number Farahani, Drezner, \& Asgari (2009) mentioned that there is single relocation known as Server or several relocations. Lastly, relocation expense depends on existing and future facility location.

There are factors which influence on relocation decision significantly such as expenditure of land acquiring, bordering permission, moving equipment and staff and etc., prompt distribution to clients and accessibility, reachability to suppliers, convenience in accessing to transit points, tariff inducements, labor condition and workforce relationship management. Furthermore, one of the most applicable areas of FLRPs is Emergency Medical Services by which decent responding time to the medical events is assured. (Min \& Melachrinoudis 1999.)

Multi-period (discrete time) vs. single-period (continuous time) facility location problems:

Three results can be obtained by utilizing multi period facility location. First, proper time period regarding facility sites decisions, second defining the best locations, and third created opportunity for firm regarding analyzing the desirable/undesirable demand fluctuation in business market in multi period time planning while such an opportunity does not exist in single period facility location problems. Furthermore, Dynamic models provide a situation in which companies are able to work more on adjusting the parameters efficiently in each of time periods compared with single period that company persons rarely are capable to deal with indefinite factors. (Miller, Friesz, Tobin, \& Kwon 2007.)

Wesolowsky \& Truscott (1975) introduced a model in which objective function acts as cost minimization, and three kinds of cost were considered in the model; first, cost of allocating 
facilities to the related demand node, second, cost of elimination facilities from the existing point and third establishment cost of new facilities to the corresponded demand node.

\section{Time-dependent facility location problems:}

Drezner \& Wesolowsky (1991) proposed a model which is similar to dynamic models but, in fact it performs effectively in real life cases with seasonal demand. TDLP problems mostly focus on defining two parameters; time of altering facility site, and location of new facility in each time period.

Stochastic, probabilistic, and fuzzy facility location problems:

While Dynamic models mostly deal with facility location scheduling, setting optimized location which conforms to all parameters is a demanding challenge for decision makers, because factors like expenses, demands and shipment period are probably indefinite during development period. (Boloori Arabani et al. 2012.)

Uncertainty can be derived from two sources; future conditions might lead to uncertainty or lack of knowledge regarding defining the parameters quantity causes ambiguity condition. (Owen \& Daskin 1998.)

In order to handle uncertainty condition, two methods have been employed. Probabilistic or Stochastic approach in which model parameters have been defined by probability distributions, and Scenario planning (robust) method in which likely values for each factor or variable has been taken into account. In the second approach it is considered that factors are inexact and there is no data regarding probabilities. (Boloori Arabani et al. 2012.)

Furthermore, the first type of the problem was suggested by Chen, Daskin, Shen, \& Uryasev 2006; Owen et al. (1998) in which stochastic planning with scenario approach is applied.

Also, Fuzzy approach has been utilized in facility location problems which can be categorized to two sections; 1) choosing facility location, Decision Making Problem 2) Location-Allocation problem, Optimization Problem. Following approaches can be also 
applied for the first rank, "Fuzzy Analytic Hierarchy Process (AHP), Fuzzy TOPSIS (the technique for order preference by similarity to ideal solution) method, and Fuzzy information Axiom." (Boloori Arabani et al. 2012.)

Also, Boloori Arabani et al. (2012) by comparing various facilities location articles concluded that in most of cases, cost minimization objective function are utilized in which operational ,transportation and material handling costs have been considered, and other less used objective function is profit maximization.

ReVelle et al. (2008) focused on two factors which should be determined before planning the details; first, pre-defined locations of customers and second, according to objective function, facilities should be defined.

Zhang, Puterman, Nelson, \& Atkins (2012) mentioned due to aging population, the role of methodologies and approaches for improving long term homecare becomes more critical. Following this issue, in Belgium, Maya Duque, Castro, Sörensen, \& Goos (2015) performed a research on homecare service planning.

Homecare service procedure includes calling for service, pre-admission evaluating for setting patients' needs and required services, determining frequency of service (weekly number of referring, duration of service per visit, service period(weekly, monthly, and etc.). After defining aforementioned parameters, the most suitable caregiver is assigned to patient (Maya Duque et al. 2015.)

Maya Duque et al. (2015) considered two objectives; fulfilling the patients and caregivers preferences at the most possible level, and minimizing the travel distance because the company pays the caregivers travel expenses.

Following modelling restrains have been taken into account:

- Equally distribution of visits during a week for patients who need more than one service weekly. 
- Assigning the patients with more than one visit weekly to various caretakers for reducing impact of service providers' absence.

- Visits planning should be same in whole time period in order to facilitate the patients scheduling.

- Maximum working hours that caregiver can provide the health service. (Maya Duque et al. 2015.)

Three decisions should be taken regarding the simulation; planning the visits based on patients' time slot, assigning the service providers to patients for each appointment, the order of different visits which caregivers should provide for patients.(Maya Duque et al. 2015.)

Instead of weighted approach for resolving the bi-objective problem, two staged method is utilized. First service level was maximized without considering the second objective, and in next level, total travel distance was minimized with specified amount of allowable decrease in service level. Resolving process contains numerating all potential visits pattern and then choosing the optimized ones between them for both objectives. (Maya Duque et al. 2015.)

Decision support system (DSS) also was established for service planning based on common three stages methods.

- Design phase in which overall design of system, problem definition and design of solution strategy are included.

- Validation phase which contains checking the simulation with ANT/OR Simulation software supporters, consulting and presenting results to area manager, running the simulation for two months and compare the results with previous manual planning system.

- Implementation stage which project will be launched with cooperation of ICT department of region.(Maya Duque et al. 2015.)

Facility location problems were primarily resolved by linear programming in which optimal solution by considering restrictions was defined by Ross \& Soland (1980). 
Research on Taiwan healthcare management was performed in order to determine the facility location between 17 medical areas. Due to existing aging population phenomena based on World Health Organization information in this country and subsequently, highly competitive service and health sector, selecting incorrect location leads to cost increment and vague future growth. (Wu, Lin, \& Chen 2007.)

Wu et al. (2007) applied the Diamond paradigm introduced by Porter (1990) in which four main and two external factors are introduced for exploring the competitive advantages. Wu et al. (2007) mentioned the elements as "Factor conditions, Demand conditions, Firm strategy, structure, and rivalry, Related and supporting industries, Chance and Government."

Also, sub criteria for each Porter's model factor was defined as following; Factor circumstances (Assets, Workforce, State ), Demand conditions(inhabitant quantity, Density, Age category), Company Policy, organization, and competitiveness (Management Purposes, Competing Hospitals level, headquarters' behavior ), Allied and supporting businesses (The healthcare segment, The treatment operations and pharmacological segment, Healthcare unit administrators ), Government (Qualifications and standards for Hospital establishment, Government determination for Health, Attempts for healthcare system improvement, Setting rules that require a hospital evaluation) and Chance(drastic variation in market demand, sudden changes in manufacture expenses, substantial alterations in exchange rate and monetary markets). (Wu et al. 2007.)

Saaty (1980) introduced Analytic hierarchy process (AHP) which breaks down the complicated multi criteria issues into hierarchy and compares pair-wise options for evaluation. Wu et al. (2007) utilized AHP in the research and AHP Eigen values, consistency experiments, elements weights, sensitivity analysis for three suggested areas were calculated and location with highest score was chosen as optimal location.

The research was performed on organ transplant process which is buffered by time rather than capacity or inventory. The process was represented by variables demand and supply and two constrains. Cold ischemia-time is the first restriction which is maximum time period 
organ can remain outside the body. The second constrain is static capacity because by donor death, organ will be available for transplantation demand and that's the reason why there exist long queues for it. (Beliën, De Boeck, Colpaert, Devesse, \& Van den Bossche 2013.)

The model was developed with objective of minimizing the waiting time by defining set of optimum transplant centers for each organ when they become available. Also, different weights are considered for each time factor in order to change the importance of factors. (Beliën et al. 2013.)

Mixed integer linear programming was applied for this issue in the context of facility location. The model results covers the purposes such as costs related to installation and transplant operations and responsiveness regarding decreasing the period between giver announcement and organ implantation.(Beliën et al. 2013.)

Beliën et al. (2013) utilized the modelling in a Belgian case including various scenarios on real data between 2004 and 2009 and following results are obtained; if the aim is to minimize just ischemia-time, then with few numbers of centers, centralization would occur and if purpose is to decrease the period elapsed between giver announcement and organ implantations, then decentralization with many centers should be considered. (Beliën et al. 2013.)

Beliën et al. (2013) mentioned also reducing ischemia-time would lead to increasing the connections between donor hospitals and centers. Also, budget constrains would result in reducing centers number and subsequently decrease in service level.

Mestre, Oliveira, \& Barbosa-Póvoa (2015) performed a research on hospital strategic planning which is about how to decide regarding hospital location and capacity allocation.

With decision on the two aspects, hospitals can handle future demand and supply. Particularly, decision on hospital location is critical, due to huge investment on hospital construction and impossibility to change the location again in future. During planning the health systems, managers need to consider various objectives which usually include 
improving access to health centers and minimizing cost. Actually, these objectives are in conflict, for instance, for improve geographical access to hospitals, health centers ought to build with smaller facilities and nearer to population which lead to increase in cost and inefficiencies. (Mestre et al. 2015.)

Mestre et al. (2015) performed a research based on NHS structure in which policy makers have to take into account planning health resources based on population needs within the limited budget.

(Kall 1994; Birge 1997) stated that there are dicisions which should be taken without complete information and unknown parameters; first stage decisions, and ones when uncertaintiy is discovered known as Second stage decisions.

Therefore, Two models location allocation have been proposed; a model in which location at first step is defined and in next step, decisions regarding allocation of resources are taken when uncertainity is revealed. Second model in which facility location and resource assigment, both are defined in initial phase. More in detail, healthcare services include two types; DH with lower service level and closer to population and $\mathrm{CH}$ with higher service facility and lower number. Also, author has taken into account to assign the nearest hospital to population. (Mestre et al. 2015.)

Following factors have had influnce on uncertainity in demand for hospitals; lifestyle, individuals expectation, population growth, technology,workforce,communication and information.(Royston 2009.)

Mestre et al. (2015) predicted the healthcare delivry rate based on demography and utilization rate, and she considered pessimistic, baseline and optimistic scenarios for healthcare demands.

Optimization modelling was designed with two objective function presenting access and cost objectives. Healthcare information from three regions in Portugal were utilized to predict modelling parameters. (Mestre et al. 2015.) 
Modelling was performed by mathematical formulation in GAMS software and problem restrictions were capacity facility, travel distance and demand fulfillment. By comparing the results, it was discovered that the second model, has more flexibility for healthcare planning networks. (Mestre et al. 2015.)

Mahar, Bretthauer, \& Salzarulo (2011) also investigated on how to locate health services in multi hospital networks, and they focused on particular facilities such as Magnetic Resonance Imaging (MRI) because manageing of these health services is difficult in low population areas. Bolus (2009) stated that expense of MRI machines is 1.2 million dollars and it requires experts with maintanance.

Frost \& Sullivan (2003) mentioned 51 percent of MRI machines are outsourced and lack of MRI experts has direct link with equipment cost. Kisken (2008) suggested transfering patients to close hospitals which have extra capacity ,medical professionals and facilities could improve health services and reduce the pressure on the hospitals with restriced medical resources

With resource pooling, there is a possibility to decresing in healthcare costs and imroving health services to patients.(Mahar et al. 2011.)

Pooling resources can bring expense saving for health systems, but on the other hand, when pooling strategy is utilized more, patients have to travel more to reach health centers.Travel distances to hospitals is global challenge due to it restricts the access to health centers and it has consequences on patients health.(Mitropoulos 2006.)

Mahar et al. (2011) developed a mathematical model to define where and how many hospitals are required, levels of service capacity, and what type of patients should receive services in which health centers.

Various types of expenses have been taken into account in the modelling including highly expensive equipment such as MRI machine, medical staff, and expenses combined with equipments such as hospital beds. Transfering patient between the hospitals and unfulfilled 
demand cost due to capacity limitations are also considered. Furthermore, the two scenario evaluate cost of every optimum solution; all the hospitals present the specilized services with their own capacity limit, and only one health center is responsible for fulfilling demands of whole network. (Mahar et al. 2011.)

Dokmeci (1997) investigated on defining size,location and number of health centers in hierarchial networks with objectives of minimizing costs of travelling and facilities based on service limitations.

Verter \& LaPierre (2002) performed a research on optimization of number and location of preventive health centers to entail the maximum number of patients in maximum covering problem context.

Oliveira \& Bevan (2006) designed two models; first one which distribute capacity utilization equally between health facilities and second model which minimize the travelling distance between health centers and geographical regions by considering how patient demands and flow would change based on health facilities suppliment.

\subsection{Patient flow}

Patient flow is significant element which influence on healthcare services performance. Hall, Belson, Murali, \& Dessouky (2006) described the patient flow study as investigation on the ways which patients are transferred inside healthcare organizations.

Alexopoulos, Goldsman, Fontanesi, Kopald, \& Wilson (2008) mentioned that many factors influence on patients entering health system rate such as hospital location, periodic and local elements.

Bhattacharjee et al. (2014) mentioned that patient flows in healthcare centers are similar to queuing structure which contains system structure (entry and exit points, paths between points, different single and multi-server nodes), patients and resources. Hulshof, Kortbeek, Boucherie, Hans, \& Bakker (2012) explained that all type of patient flow including operative 
or clinical in any care process such as outpatient, inpatient, surgical, or emergency care, are considered as multi stage problem.

From operative type view, patient flow is constructed from various steps such as registering, consulting, performing medical tests. From clinical point of view, patient flow is built based on stages which express the patients' health condition, for instance, a person referred to geriatric section, may require long time care or serious problems. (Bhattacharjee et al. 2014.)

Jiang \& Giachetti (2008) stated that there is no necessity that each patient has to pass through all stages and each stage includes common tasks such as arriving, waiting, receiving service and leaving the block.

Major cause of uncertainty is arbitrariness in inter arrival time of planned and non-planned patients, not showing up of planned patients, volatility in service time in different phase of care, uncertainties regarding transition of patient health situation and movement between different health locations. (Bhattacharjee et al. 2014.)

Reasons of complexity in healthcare include that there exist different care pathways for patients in all subsystem of hospitals which depends on factors such as severity level of patient health, doctors' decisions, different rules for pathways and resource limitations. There are several and large phases which patient has to pass. Also, in some cases, patient requires a combination of large stages. (Bhattacharjee et al. 2014.)

Many rules prioritize patients to be visited by doctors or radiology sections. Furthermore, there exist various policies for patients' admission and even assigning beds to different patients. (Bhattacharjee et al. 2014.)

Regarding simulation of patient flow, Bhattacharjee et al. (2014) mentioned that patient flow modelling has significant benefit for hospitals service administration by offering visions for enhancing procedure, resource development, capacity allocation and planning, and appointment arrangement. 
Various analyses can be obtained from patient flow simulation such as exploring the most important factors which influence on the health procedures, assessing the current appointment scheduling system with other possible alternatives in order to improve scheduling and sequencing rules, improving resource utilization by analyzing other potential resource allocation rules and planning, exploring the other possible care routings and defining the best pathways and resulted improvements, evaluating the cost of care by patients lengths of stay, investigating on relationship between process parameters in different phases, categorizing the patients to various groups and then applying different planning methods for different groups.(Bhattacharjee et al. 2014.)

Harper \& Shahani (2002) also mentioned that modelling should be performed with stochastic nature such as stochastic arrival, service time and patients routing.

Bhattacharjee et al. (2014) explained the various modeling aspects which should be included in modelling. First point is network structure which includes number of nodes and server number in each node. (Gunal 2012; Lowery 1996) expressed that network configuration is also first aspect to be considered. Ross (2009) explained that in Markov process modelling also structure supports to specify the states and possible transitions between them.

Bhattacharjee et al. (2014) stated that patients arrivals randomness has been modelled based on following literatures(Côté 1999; Gorunescu, McClean, \& Millard 2002a, b; Harrison, Shafer, \& Mackay 2005; Jiang et al. 2008; Yeon, Lee, \& Jang 2010) according to homogenous and non-homogenous Poisson distribution.

Alexopoulos et al. (2008) described Poisson assumption for planned and nonscheduled patients arrivals are violated and recommend utilizing non-homogenous Poisson for patients' arrival and patients' delay based on Johnson's distribution.

During the care procedure, patients move through different routes in health system. Different patients' type choose various paths which some of the routes can be similar and rests different. Various spots have possible diverse transitions to further states and even dissimilar 
patients' category have numerous probabilities of transitions between states. Defining the probabilities should be performed according to examining the earlier information on patients' pathways. (Cochran \& Roche 2009; Côté \& Stein 2007.)

Consultation time with doctors, registration time at reception, and performing medical experiments time included in service time duration are uncertain variables and probability distribution for these variables should be modelled. Also, mostly for inpatient and outpatient service, exponential time is considered. Other probability distributions which have been utilized are Weibull, gamma, lognormal, triangular, and other combinations of exponential distribution. (De Bruin, van Rossum, Visser, \& Koole 2007)

Scientists have applied various types of modelling methods which are described as following.

\section{Analytical methods:}

It is categorized to two groups; Queuing theoretic and Markov chains \& compartmental models.

Queuing theory models have being utilized from 1950 and it has being evolved. Performance indicators are calculated by analytical formulas developed in queuing theory such as servers' efficiency, idle time measurement, congestion and waiting time indexes, and analytical results are limited to Markovian models. (Bhattacharjee et al. 2014.)

"M/M/1, M/M/c and $\mathrm{M} / \mathrm{M} / \mathrm{c} / \mathrm{c}$ " models are considered as subcategorizes of Markovian models in which assumptions such as patient arrival by Poisson and service time by exponential distribution are considered. Also subcategories of Non Markovian methods include "M/PH/c/c, M/PH/c/N, G/G/1, and G/G/m" approaches. (De Bruin et al. 2007; Green \& Nguyen 2001.)

Gorunescu et al. (2002a) introduced M/PH/c/c queue for patient flow in geriatric department which PH represent stage category and C signify the entire beds number. Gorunescu et al. (2002a) mentioned in the model, when all the bed are captured, the coming patient would 
disappear from system, which it does not occur in reality and patients refers to hospitals later or admitted to other specialties.

Gorunescu et al. (2002a) in his modeling, also looks for minimum required number of beds. Gorunescu et al. (2002a) also described "M/PH/c/N" queue theory in which $\mathrm{N}$ is full capacity of the sector and effect of having extra beds for time of crisis on system is also considered.

De Bruin et al. (2007) applied the "M/M/c/c" for cardiac emergency section in order to explore care process bottleneck and optimized bed allocation, maximum number of rejected admissions, relationship between LOS, arrivals variation, and occupancy rate.

Green (2006) explained analytical queuing models are practical if complexity level is average, but in more complicated systems such as health centers with various integrated facilities simulation modelling is more beneficial.

Analytic queuing theories have being applied for many years in different hospital sections such as resource allocation in ED department and ICU, appointments planning in outpatient section or radiology department. (Bhattacharjee et al. 2014.)

Reviews of recent articles demonstrates that analytical queuing models has been used majorly in one phase procedures such as inpatient sector in which ward is represented as several server nodes or in clinics where doctors are considered as servers. (Bhattacharjee et al. 2014.)

Queuing theories have been utilized for fixed status investigation while utilizing transient analysis can be troublesome. On the other hand, because many hospitals work for fixed time period in a day, then it will not reach to steady state, and transient nature of analysis should be considered. (Bhattacharjee et al. 2014.)

Various aspects has been used for describing queuing modeling theories such as single server versus multi-server versus infinite server, exponential as opposed to non-exponential (or Markovian versus Non-Markovian), steady-state against time-dependent, single-node queues 
versus queues network, and additional features, such as priority systems, server vacations, batch arrivals, balking and reneging of customers. (Worthington 2009.)

\section{Markov chains and compartmental models:}

Markov chains contain probabilistic procedures with various states in which the state distribution does not depend on previous state conditions and it is related to present system state while in semi Markov chain, transitions are completed by specific probability distribution.(Bhattacharjee et al. 2014.)

Patient flows for care process in hospitals also are completed by different states which can be characterized by Markov chain. These models can be utilized by defining patient number

for future for evaluating patients' lengths of stay, spent time in each state, resource allocation, cost estimation for care process. (Bhattacharjee et al. 2014.)

Markov chain has not being majorly utilized for patients flow as compared with queuing modelling theories; however Markov chain as analytical tool is associated with queuing theories. (Bhattacharjee et al. 2014.)

McClean, McAlea, \& Millard (1998) implemented the Markov chain modelling for patients flow in which three different cares were considered; severe, long-stay and rehabilitative care.

The model was designed in a way that the cost for each care was assigned to model and then the expected cost for each group is calculated which could be beneficial for healthcare managers. Also, probability values of each group can be adjusted and resulted information can be used for comparing various strategies.(McClean et al. 1998.)

(Haifeng, Chaussalet, \& Millard 2006; Xie, Chaussalet, \& Millard 2005) introduced the Markov model with continuous time in order to analyze the lengths of stay for older patients who transport between their home and nurses' location. 
Marshall \& McClean (2004) worked on modelling of older people period of time staying in hospital for resource allocation with considering the fitted distribution for categorizing the LOS of patients based on factors such as age, sex, admission reasons, and etc.

After grouping the patients based on LOS in the modelling, common features of each group were determined by investigating on patients details with respective lengths of stay. This model contributes managers to optimize the process of bed allocation and also assess the patients' lengths of stay by examining the common characteristics. (Marshall et al. 2004.)

Garg, McClean, Meenan, \& Millard (2010) introduced a different version of Markov model with discrete time period for ward admittance and capacity development in a care system in which treatment is provided both in society and healthcare centers.

Various types of modelling such as Agent Based, System Dynamics and Discrete Event Simulation have been utilized in healthcare problems. System Dynamics Modelling is majorly used for long term predictions and is more applicable when system is analyzed at large scale. On the other hand, discrete event simulation is suitable when patients' flow of each individual is to be examined and operational level decisions have to be taken. (Katsaliaki \& Mustafee 2011.)

Patients flow simulation in which extremely complicated procedures are included, analytical models cannot be applied due to it requires massive data and expertise. Also, analytical methods may not be valid in special situations. (Bhattacharjee et al. 2014.)

Gunal \& Pidd (2006) performed a DE simulation of patient movement in emergency section for analyzing effects of factors which influence on the healthcare performance indicators such as number of patients with lengths of stay more than 4 hours.

Findlay \& Grant (2011) performed a research in army clinic for examining the operational strategies along various alternatives in order to discover the operative changes which increase clinic efficiency. 
Findlay et al. (2011) in the modelling considered patients' arrivals to health center were based on batches with random arrival time and batch size, and for promoting the performance, launching the appointment and Walk-In systems were suggested.

Holm \& Dahl (2010) investigated on DE simulation of urgent ward patient movement and analyze the impact of increasing the patients flow number on department performance .Also, usage of extra resources in case of increased patients flow were identified by the simulation modelling.

Discrete event simulation of patient flow is mostly applied in outpatient context and emergency department because of patients flow complexities and time related feature of these environment. (Bhattacharjee et al. 2014.)

Bhattacharjee et al. (2014) also designed a framework for patient flow modelling which consists of four stages as following;

Initial Understanding: This phase includes observation of different procedures of health center and discussion/interview with executives and hospital personnel. (Bhattacharjee et al. 2014.)

Data Collection: This stage contains respective information gathering to define the system features such as patients' arrival pattern, transition probabilities between states, service degree of different service processes. (Bhattacharjee et al. 2014.)

Data Analyze phase: The purpose of this step is identifying patient arrivals, service time and related factors probability distribution, categorizing of patients to different groups, identifying probability distribution of transitions between states. (Bhattacharjee et al. 2014.)

Patient flow modelling phase: In first step, modelling technique should be chosen based on facing issue and required analysis and, then simulation model is built according to information gathered from data collection stage and calculated parameters from data analysis stage. (Bhattacharjee et al. 2014.) 


\section{Performance Analysis Phase:}

In this phase, different performance indicators are investigated to discover the relationship between performance indexes and elements influence on system performance by analytical methods, numerical approaches, analytical formulations approximations, and diverse scenarios simulations. (Bhattacharjee et al. 2014.)

Health service management is always challenged by factors such as high rate of individuals involvement including patients and resources, budget and sources shortage, high number of variables (employee scheduling, beds number, and etc ), confusion regarding demands and health service outcome. Furthermore, patients besides requesting for high service quality, do not prefer to stay in queue for long time to receive the service. on the other hand it is stated that concept of healthcare systems has switched from the resource usage optimization to detection of balance between patients services and efficiency for providers. (Waleed AboHamad 2013.)

Waleed Abo-Hamad (2013) also investigated on healthcare management with simulation and combining it with quality tools.

Waleed Abo-Hamad (2013) as first step of research, designed a framework with purpose of supporting the simulation modelling procedures and communication tool for validating the model with people working inside the actual system.

Conceptual framework entails following steps:

1- Formulation and Understanding phase which contains data collecting from observations and interviews with hospital staff. (Waleed Abo-Hamad 2013.)

2- Conceptualizations and analysis step which includes building business process flow map based on data collected, finding and assigning resources to activities, setting criteria for Balanced Score card method. (Waleed Abo-Hamad 2013.) 
3- Simulation modelling translation and validation of results, performing What if scenarios analyzing various outcomes, selecting goals based on multi-criteria decision analysis (MCDA) by top managers. (Waleed Abo-Hamad 2013.)

Waleed Abo-Hamad (2013) conducted the research on one of the well-known Dublin hospital which had overcrowding and long waiting time issues in emergency department.

Following steps for the simulation modelling were considered; ED layout which include hospital department and sections; ED staff containing individuals profession, number of employee and working hours; defining key performance indicators, KPI; patient flow analysis which includes procedure of treatment from when patient enter to hospital; ED process mapping in which Integrated Defination modelling toolbox, IDEF process for modelling the complicated systems is utilized; Empirical data analysis in which author analyzed hospital database information in order to gain qualitative data such as patterns of patients arrival, patients grouping and routing data. (Waleed Abo-Hamad 2013.)

Waleed Abo-Hamad (2013) defined two types of indicators; patient output and ED competence" . For Patient output, he considered average waiting period and average length of stay (ALOS) and ED productivity, and resource utilization, layout efficiency for ED efficiency.

Result of simulation validation and verification also can be performed by three ways; Face Confirmation, Comparison analysis and hypothesis testing. Interviews are performed with managers and nurses in order to approve the simulation results in face testing. In second method output of simulation model is compared with real health system results. (Balci 1997.)

Scenarios which are suggested by managers can be used in scenario analysis. Senior managers proposed to increase ED capacity and employees' level. Between scenario options, transferring the people waiting to a temporarily delay section, has decreased significantly ALOS and nurses travelling distance. (Waleed Abo-Hamad 2013.) 
One step further of pure simulation, Waleed Abo-Hamad (2013) built a preference model based on outcomes of all scenarios and inclination scale in several attribute evaluation (PRIME).

Oddoye, Jones, Tamiz, \& Schmidt (2009) investigated on MAU healthcare section. MAU resonsiblity includes rapid evaluation of acute patients medical conditions who are refered to hospitals by emergency department, accident or general physicians (Carrol.L 2004).

Lack of balance between released and incoming patients leads to delay in MAU unit. Also Doctors and nurses workload increases due to lack of sufficient number of staff to respond the patients needs. Number of beds also play critical role on patients waiting time, for instance, patients waiting for transfering to other hospitals causes bed blockage and prevent other patients to be admitted. (Oddoye et al. 2009.)

Robinson (2004) explained three diferent type of data; Available, not available but collectable, not available and collectable. Oddoye et al. (2009) considered second category for his research, and noticed also 95 percents of incoming patients require bed assignment before admission.

Oddoye et al. (2009) simulaed a model with considering patints flow from admission, medical test, visiting nurse, doctor, consultancy and discharge procedures.

Oddoye et al. (2009) mentioned that two major factor which affects long time waitings are availibality of bed before transfering patients to MAU unit and staff are usually busy in ward with transfering patients and it lasts long to become available again.

Oddoye et al. (2009) measured three facors with the simuation results; total lenghs of stay, queue length and waiting time. Also, effects of elements such as decrease in number of doctors,nurses and staff due to illness, increase or reduction of beds number, adding second medical consultant on the system performance was also investigated (Oddoye et al. 2009). 
Oddoye et al. (2009) examined also combination of goal programming(GP) with simulation modelling.

GP was performed in order to define the the efficient resource usages. Therefore, management could decide regarding tradeoff between beds number, queue length, and waiting time based on management preferences. Simlulation outcomes are considered as input for GP model and weights for five objectives with positive variation based on management preference are utilized. (Oddoye et al. 2009.)

Five objectives include patient queue for nurses and doctors; total length queue in system; queue waiting time and beds number. The objective function act as minimizing deviaiton from beds, wating time and queues. Also,reaching mentioned objevtives lead to reducing the stress level of staff and boosting the patient satisfaction. Further more, Manhattan L1 method was applied for goal programming and it was discovered increasing beds would significantly improve the MAU unit performance.(Oddoye et al. 2009.)

System engineering (SE) methods in order to investigate on complex healthcare systems have been utilized broadly. In other word, it is less probable to design health systems within engineering context, but the focus is placed on utilizition of SE approaches to enhance system performance and results. (Rouse 2000; Rouse et al. 2010; Unknown 2006.)

Basole, Bodner, \& Rouse (2013) launched a research with purpose of designing Serious games in order to explore strategies which maximize the healthcare performace and discovering potential health softwares in education for health and business related institutions.

Basole et al. (2013) applied organizational simulation in his reseaarch which includes modelling of business procedure, individuals and group behavior, decision logic, organizational operations and value modelling, and it leads to obtain insights regarding trades-off between information complixity management and efficient decision making in healthcare systems. Basole et al. (2013) mentioned also that his simulation area is derived 
from supply chain domain in which goods are produced and assembeled from sources and delivered to facility networks and then customers can access the products in last stage.

Basole et al. (2013) also stressed on the role of decision support systems based on modelling in healthcare and also for resolving its complixity, the author mentioned following detailed information are required;

- Medical phenomena, interventions and progression over time;

- Organizational and inter-organizational processes that dictate, among other things, patient flow and information flow;

- Costs, reimbursement and capitation rules, and trade-offs between cost and health outcomes;

- The effect of incentives and information on individual actor behavior and overall system performance. (Basole et al. 2013.)

Basole et al. (2013) modelled a health advisor in his research which manages health services delivery for patients by evaluating and monitoring their health requisite and introducing them to health service providers for treatment and medical tests.

Therefore, the health advisor by accessing to information refers patients to health service providers which improve the customers' results either by reducing cost or enhancing their health outcomes. (Basole et al. 2013.)

Clients by considering factors such as age, gender, lifestyle, race, stress level, diet, exercise, and health service providers with primary care physicians and specialists' types associated with each one cost and quality are major game characters. Also, different diseases "severity levels such as Asymptomatic, Symptomatic, Chronic, and Acute" are considered in simulation design. (Basole et al. 2013.)

Furthermore, transitions between severity levels are possible based on probabilities collected from medical resources and experts comments. Authors designed emotional state for patients such as "neutral, nervous, confident, know-it-all, passive, and collaborative" in order to estimate closeness level of client statements regarding illness to reality. (Basole et al. 2013.) 
Olsen, Aisner, \& McGinnis (2007) stated that access to valid, precise and comprehensive medical information sources has significant impact on health delivery. Therefore, Basole et al. (2013) utilized two major information sources; Electronic Health Records (EHR) software systems which save massive medical information, and also dialogs between provider and patients; Medfile which contains information regarding diseases associated with symptoms, required clinical experiments and treatments.

Basole et al. (2013) research was hypothesized based on "crowd sourcing notion". (Howe 2009; Surowiecki 2005) stated when high number of people indicate a problem, probably it will lead to innovative and important solutions for promoting healthcare delivery quality.

Therefore, Basole et al. (2013) performed the simulation with serious games approach and four group of participants; senior healthcare doctors, healthcare experts in training, interested college students without experience in healthcare, youths with solid experience in playing games.

The overall purpose of the investigation is to exploring systemic alteration in health service provision such as proposing innovative commercial methods. Feedbacks from game participants include:

- Learning aspect increases by playing game;

- Physicians prefer to treat patients instead of referring by new model;

- As the complexity increases, players' performance reduces.

- Access to updated information sources extremely influences on healthcare delivery. (Basole et al. 2013.) 


\section{RESEARCH METHOD}

In order to resolve challenge for management, simulation modeling is utilized to examine regarding location of health centers and derived possible outcome on service level. Also, by simulation, evaluating various scenarios for managers would be possible.

Considering the problem context and required elements for modelling, Anylogic software is used in this problem.

Due to the fact that healthcare management problem is involved with patients and it is inherently individualistic problem, agent based simulation is also utilized.

Agent based simulation, from practical point of view, is a decentralized and individual centric method. Modeler define agents which can be people, company, city, goods, etc. Then, behavior or activity of each agent is determined and they are placed in an environment. Modeler can design the relationships between agents and perform the simulation to evaluate the results derived from agents' interactions. 


\section{METHOD AND MATERIALS}

\subsection{Agent Based simulation}

Agents are blocks of simulation modelling and each one can contain different process or action. Three different agent types are created for simulation modelling; Patient, HealthCareCenter, and Doctors.

Each Patient agent, based on classical method of SIR; Susceptible, Infectious, and Recovered has different states in simulation time period. In other word, Individuals initially are susceptible to disease which means they are in exposure of disease or have the potential of becoming sick.

Based on a triangular probability distribution, susceptible people become sick and their state changes to infectious. For a time period which disease lasts to advance inside the body and emerge from latent condition, triangular probability distribution is considered and then transition to next state occurs.

In the next phase, each patient based on their geographical coordinates, find the nearest health center and move toward it.

After arriving to health center, transition between MovingToHealthCareCenter and Recovering stats is triggered and patient enter the health center and process of health care service begins.

After receiving the health service in clinic, patients leave the health center. Due to cyclic nature of this process, patients after recovery, are transferred into susceptible state again.

The whole loop of disease steps, is displayed in the following figure. 


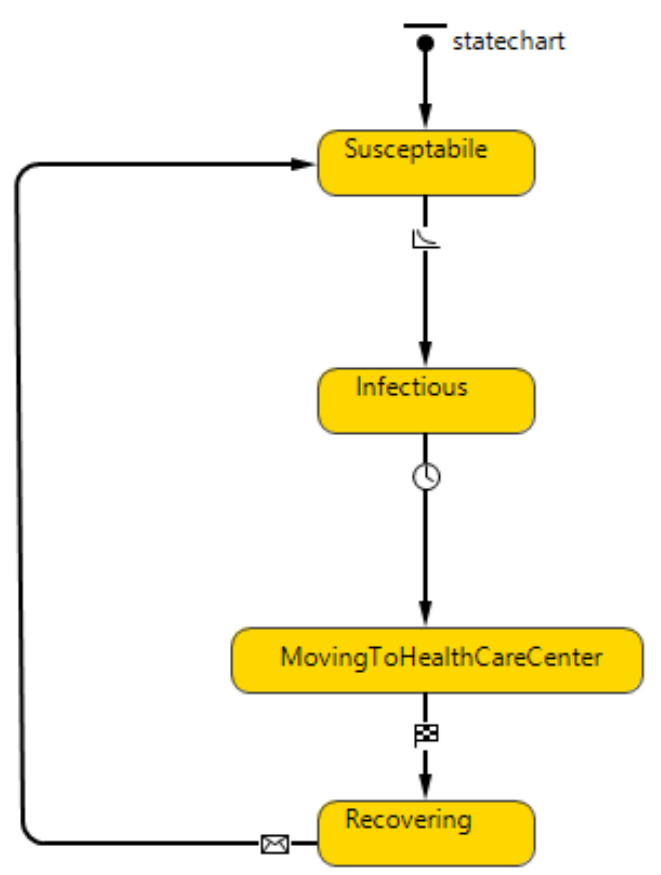

Figure 4. Patient States and Transition.

\subsection{Patient flow simulation}

There are various process steps in health centers which each patient must pass through to receive the health service. The simple four stages process is considered for HealthCareCenter agent which are mentioned as following.

Arrival: patients who have arrived to health centers, enter the care process in this phase.

Service: Patients who come into the health care, are transferred to this step in which they receive the treatment if there is available doctor, otherwise, they have to wait in queue until a doctor become accessible. Also, queue capacity is defined with maximum size and no patients are terminated from care process without seizing service. Service time is considered based on triangular probability distribution with hourly unit, and patients receive the service based on FIFO priority method. 
Resource Pool: this block of simulation is associated with service block and it contains information regarding the resources for providing health service. Doctor agent is considered as resource unit and, a working schedule is arranged for doctors in which one doctor is assigned to night shifts starting from 00.00 to $8.00 \mathrm{AM}$ and working breaks such as lunch time. For other time periods, two doctors are available. Also, working schedule is repeated for each day of week.

Time Measure Start and End: These two blocks are added to Patient flow in order to record each patient Lengths of Stay.

Exit: In this block, patient leave the health center and exit from care flow.

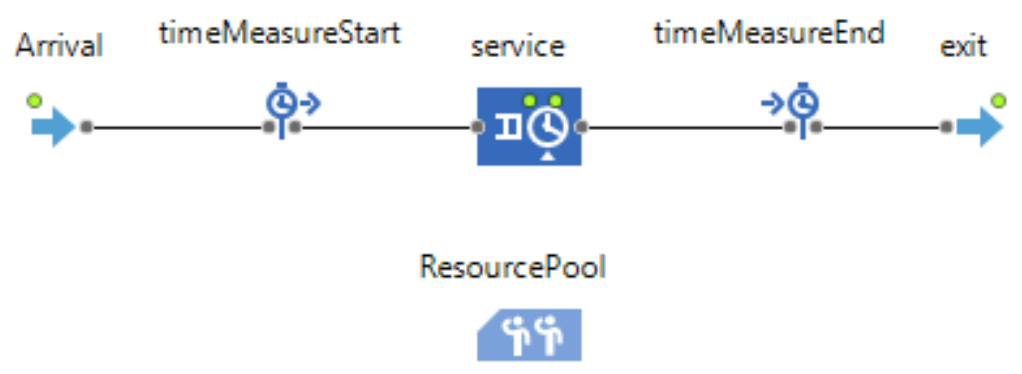

Figure 5. Patient Flow.

\subsection{Geographical information system}

Simulating the population density is performed with GIS feature of Anylogic software. Actually, a map of world is provided in this section of software, and points or regions can be explored by search tab. Information regarding map tiles, can be requested from different tile providers such as Mapquest, OSM classic, OSM German, Mapquest Satellite, Land sat, and Cycle Map. GIS feature also retrieves necessary information such as routes, regions, cities, etc and there is a possibility to select a point or area for agents' location. 
Therefore, three potential locations which are suggested from related healthcare management are defined for Hospital location, and HealthCareCenter agent is located on each city point.

The challenge for simulation is how to simulate population density which resembles to reality.

Information regarding population number by each municipality is collected from Official Finland Statistical website (Statistics Finland). Vaasa region is divided by 15 regions, therefore, regions are selected by search tab and then a Patient agent with the name of area is created for each region.

Data referred to population number is available on Excel sheet, and this information is retrieved to the software with a Java function. Also, patients population are scattered in each region randomly by the software.

As an alternative, population can be distributed also based on the population of each $1 \mathrm{~km}$ square of Vaasa region. In this method, $1 \mathrm{Km}$ square zone are located on the GIS map according to its longitude and latitude. In the next step, population number is assigned to the each region.

In the next phase, patients should detect the nearest health center according to their own and health center geographical position. This process is performed by a Java Function which specifies the nearest HealthCareCenter agent. In order to Patients transport from the initial point toward the health center, routing information is required. In Anylogic software, routing section has various options, for example, routing information can be requested from OSM server, loaded from PBF file or straight lines. Also routing method can be fastest or shortest and route types can be chosen for car, bike or foot.

In our modelling, routes are requested from OSM server, and routing method is fastest with car road type. 


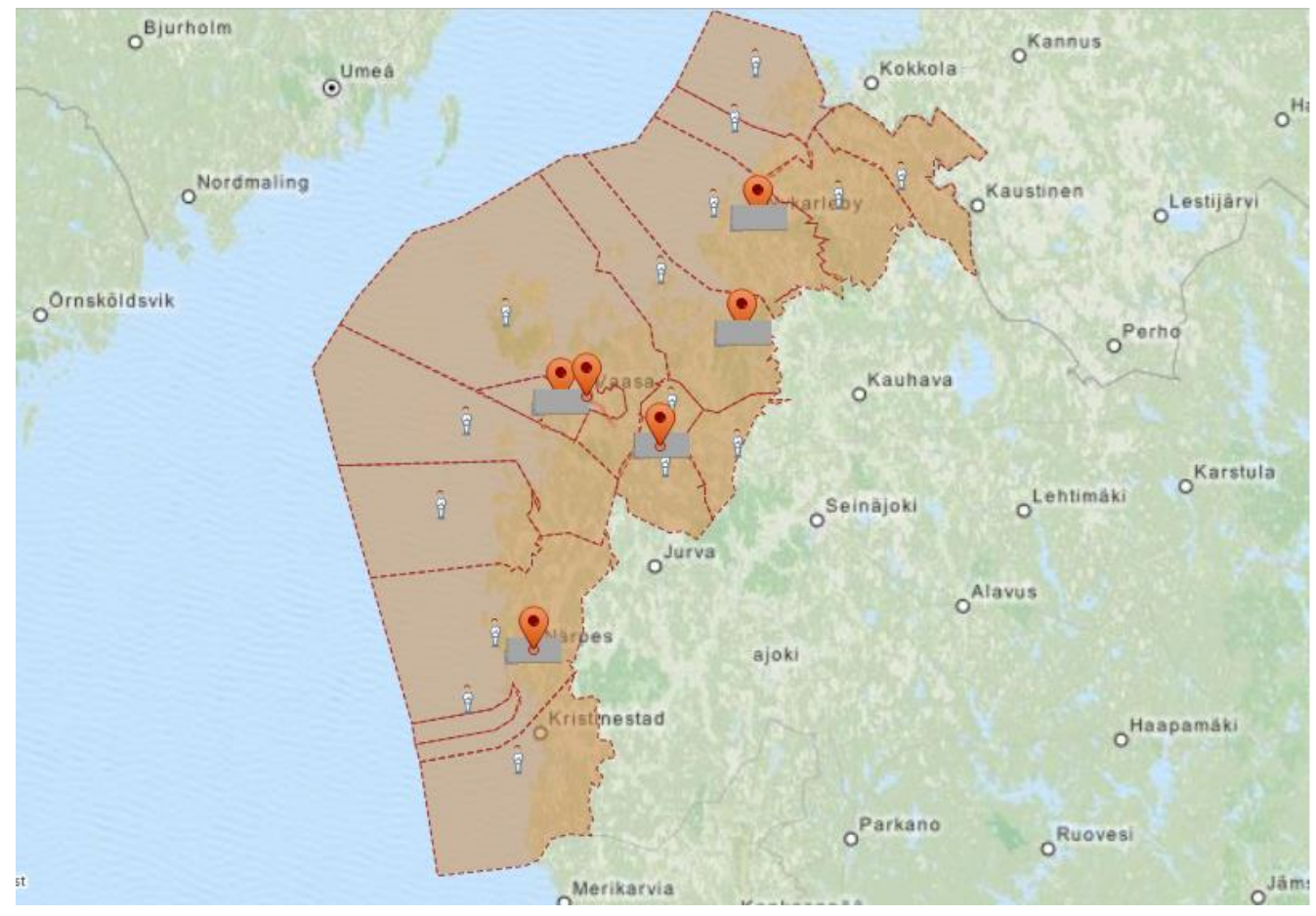

Figure 6.GIS map with regions.

\subsection{Key performance indicators}

In order to measure the output from simulation modelling, various performance indicators should be taken into account. Service level which is critical aspect for health management, is measured in the modelling by two major indexes; patients number in Queue and Length of Stay. Sick individuals number in queue is collected from Service block and demonstrated on a chart which changes along with modelling time. 


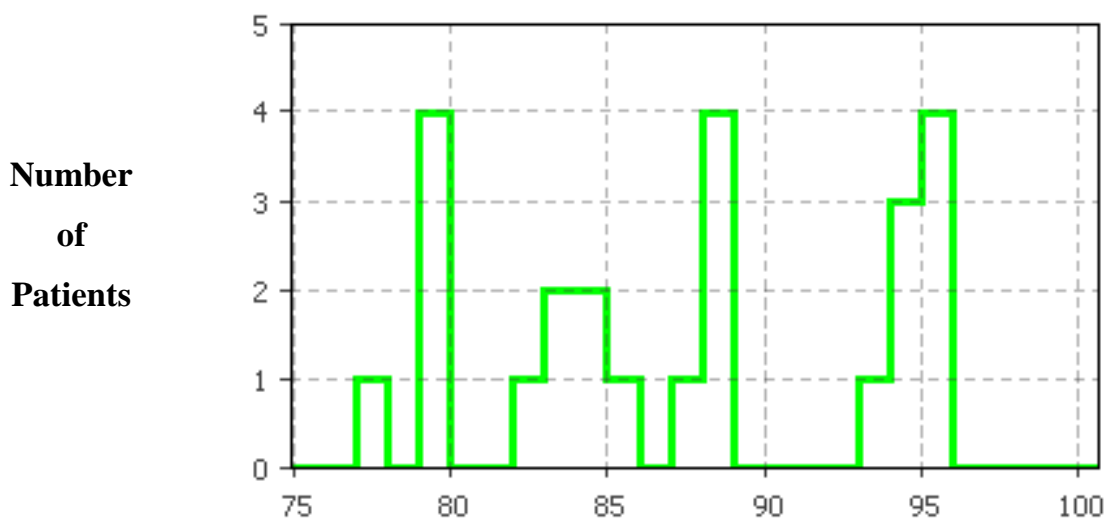

Time Period (days)

Figure 7. Number of patient in queue.

Length of stay indicates a time period from the moment patients arrive to health center until they leave the clinic. Lengths of stay is displayed with a chart which vertical axis shows LOS in hours and horizontal axis time periods. Lengths of stay is also demonstrated with three graphs which include min, max and average time. 


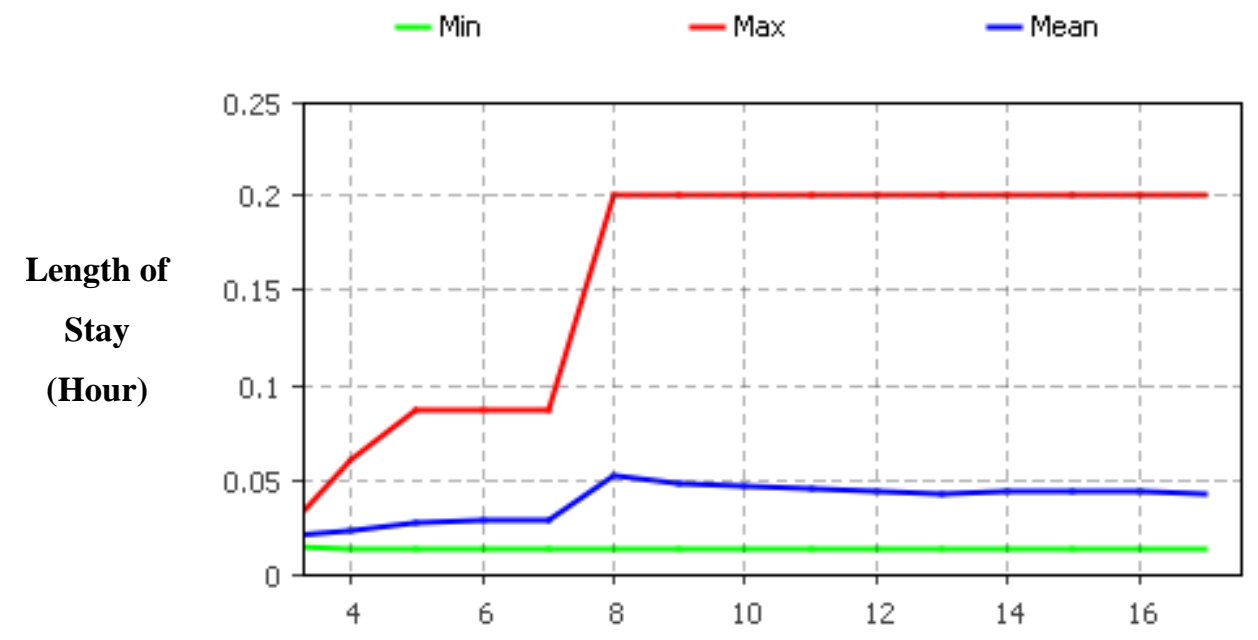

Time Period (days)

Figure 8. Lengths of stay.

Resource utilization for doctors is also measured in the modelling which shows degree of actual works to possible total working hours in percentage, and resource managers can identify if resources are over or under-utilized. In Figure 8, resource utilization percentage for a service location per day is displayed. 


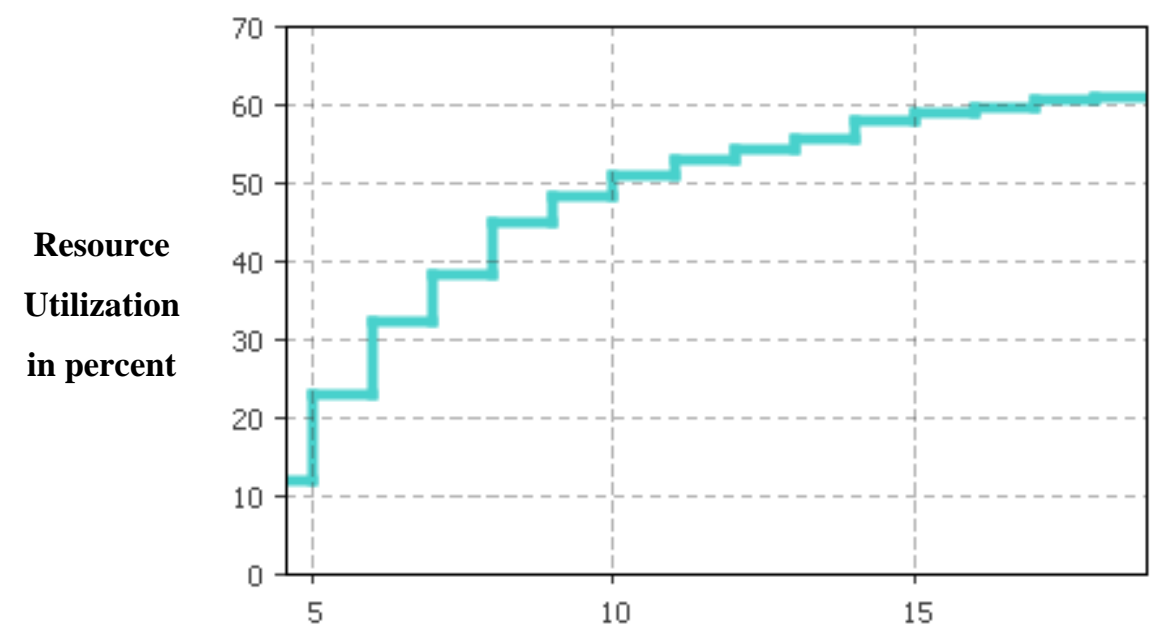

Time Period (days)

Figure 9. Resource utilization.

Also, another indicator which is applied in modelling is Number of patient ratio. Ratio between patients who enter a healthcare center and patients who depart, is displayed by a chart in which horizontal axis contains time period data and vertical axis present the number of patients in accumulative method. 


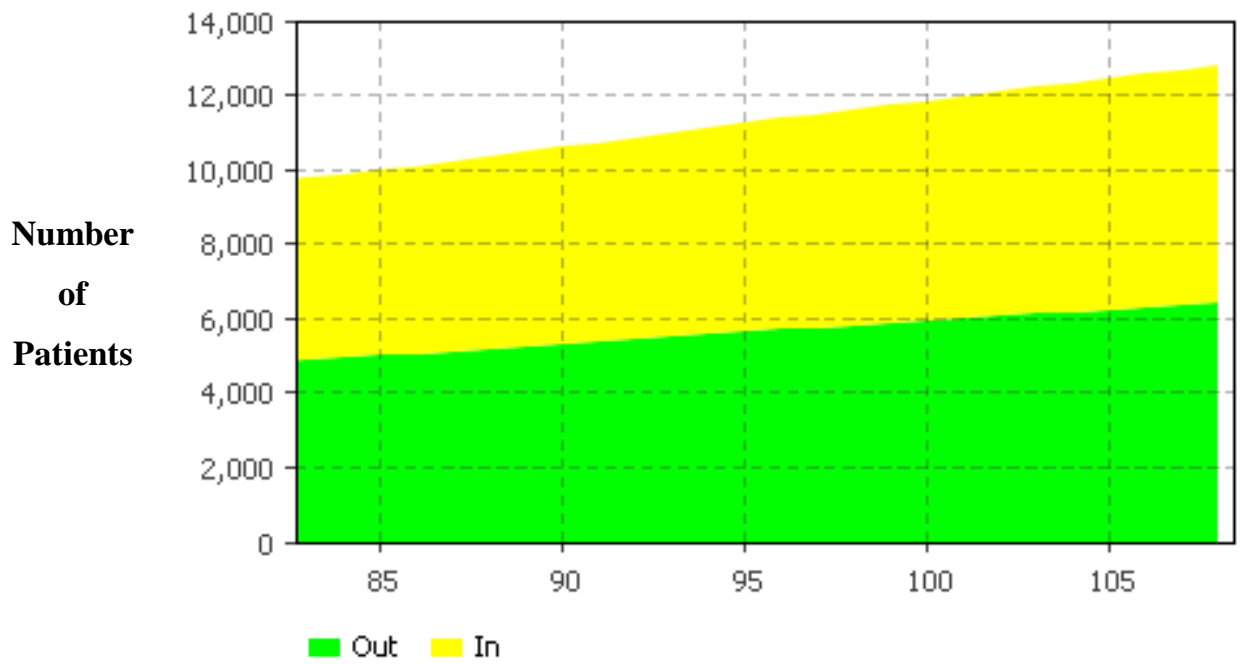

Time Period (days)

Figure 10. Number of patients ratio yielded by different of inflow and outflow.

Also, in order to add interactivity to model, slider control is designed in modelling by which managers would be able to change the number of doctors. By this option, in model running, result of decreasing or increasing of resources is displayed by the key performance indicators. 


\section{DESIGN OF EXPERIMENT}

In an experiment, some of the factors or variables are changed in order to observe the result of changes on response variables. Design of experiments (DOE) is an efficient process for developing experiments in a way that information which obtained, can be utilized for analyses and conclusions. (Nist \& Sematech 2012.)

Design of experiments commences with defining the purposes of experiments and specifying the process factors for the study. Indeed, DOE presents a precise and comprehensive plan in advance of performing the experiments. By choosing an accurate and complete experiment design, researchers can maximize the degree of information which can be obtained for a given extent of experimental effort. (Nist et al. 2012.)

The theory behind the experiments design generally starts with concept of Process Models. Generally, the process model begins with black box type included numerous discrete and continuous input factors which can be manipulated and output responses which can be measured subsequently. Also, the output responses are considered continues. (Nist et al. 2012.)
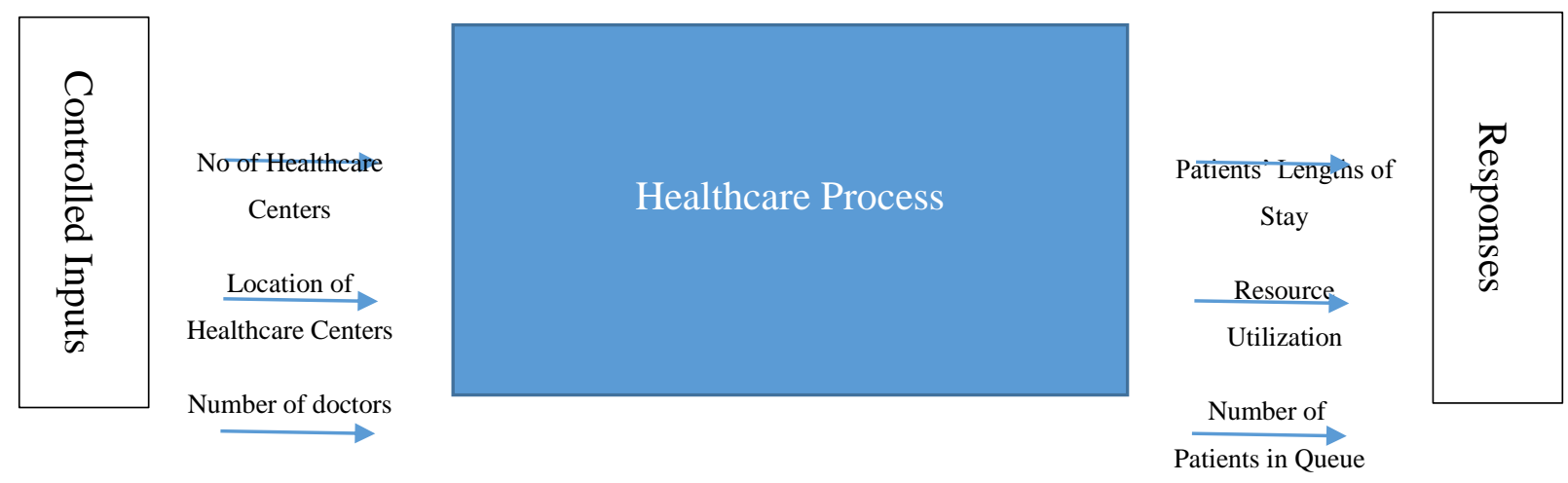

Figure 11. Black box diagram. 
As it is mentioned in previous sections, one of the simulation purposes contains defining number and spot of the healthcare facilities. Therefore, following framework is proposed for designing the experiments and scenarios.

$1 \mathrm{~km}$ square population areas are sorted ascending based on population number and healthcare centers are located also on geographical coordination of the areas .Also, four scenarios with 20,15, 10 and 5 healthcare centers are designed.

Simulation is performed for 3 month time period per each scenario, and key performance indicators are measured per each experiment and healthcare center.

Table 1. Simulation results with 20 healthcare centers.

\begin{tabular}{|c|c|c|c|c|}
\hline $\mathbf{2 0}$ & No. Patient & LOS (hour).Max & LOS (hour).Ave & Resource Utilization(\%) \\
\hline Närpiö & 0 & 0.14 & 0.05 & 23 \\
\hline Luoto & 2 & 0.15 & 0.05 & 22 \\
\hline Perho & 1 & 0.11 & 0.05 & 13 \\
\hline Perho & 1 & 0.1 & 0.05 & 34 \\
\hline Vaasa & 1 & 0.15 & 0.05 & 17 \\
\hline Laihia & 1 & 0.11 & 0.05 & 53 \\
\hline Mustasaari & 3 & 0.21 & 0.05 & 36 \\
\hline Pedersören kunta & 2 & 0.19 & 0.05 & 43 \\
\hline Isokyrö & 2 & 0.15 & 0.05 & 21 \\
\hline Kannus & 1 & 0.2 & 0.05 & 23 \\
\hline Kruunupyy & 2 & 0.15 & 0.05 & 11 \\
\hline Kaustinen & 1 & 0.15 & 0.45 & 16 \\
\hline Pedersören kunta & 0 & 0.1 & 0.45 & 8 \\
\hline Lestijärvi & 0 & 0.13 & 0.05 & 8 \\
\hline Lestijärvi & 0 & 0.1 & 0.05 & 11 \\
\hline Laihia & 0 & 0.85 & 0.05 & 61 \\
\hline Maalahti & 0 & 0.1 & 0.06 & 31 \\
\hline Närpiö & 5 & 0.22 & 0.05 & 21 \\
\hline Vaasa & 2 & 0.16 & 0.05 & \\
\hline Maalahti & 1 & 0.01 & & \\
\hline
\end{tabular}


Table 2. Result of simulation with 15 healthcare centers.

\begin{tabular}{|c|c|c|c|c|}
\hline 15 & No. Patient & LOS (hour).Max & LOS (hour).Ave & Resource Utilization(\%) \\
\hline Närpiö & 766 & 16 & 6 & 96 \\
\hline Luoto & 4 & 0.25 & 0.05 & 44 \\
\hline Perho & 2 & 0.14 & 0.05 & 23 \\
\hline Perho & 1 & 0.11 & 0.05 & 12 \\
\hline Vaasa & 2 & 0.18 & 0.06 & 43 \\
\hline Laihia & 1 & 0.11 & 0.05 & 27 \\
\hline Mustasaari & 5 & 0.24 & 0.07 & 41 \\
\hline Pedersören kunta & 2 & 0.14 & 0.06 & 36 \\
\hline Isokyrö & 2 & 0.14 & 0.55 & 42 \\
\hline Kannus & 2 & 0.18 & 0.06 & 21 \\
\hline Kruunupyy & 0 & 0.11 & 0.05 & 38 \\
\hline Kaustinen & 2 & 0.13 & 0.05 & 12 \\
\hline Pedersören kunta & 1 & 0.12 & 0.05 & 16 \\
\hline Lestijärvi & 0 & 0.1 & 0.05 & 7 \\
\hline Lestijärvi & 0 & 0.1 & 0.05 & \\
\hline
\end{tabular}

Table 3. Simulation results with 10 healthcare centers.

\begin{tabular}{|c|c|c|c|c|}
\hline 10 & No. Patient & LOS (hour).Max & LOS (hour).Ave & Resource Utilization(\%) \\
\hline Närpiö & 812 & 8 & 17 & 96 \\
\hline Luoto & 6 & 0.21 & 0.05 & 58 \\
\hline Perho & 2 & 0.23 & 0.05 & 15 \\
\hline Perho & 1 & 0.15 & 0.05 & 44 \\
\hline Vaasa & 2 & 0.14 & 0.06 & 27 \\
\hline Laihia & 2 & 0.12 & 0.05 & 69 \\
\hline Mustasaari & 8 & 0.4 & 0.07 & 79 \\
\hline Pedersören kunta & 11 & 0.35 & 0.1 & 35 \\
\hline Isokyrö & 2 & 0.14 & 0.05 & 62 \\
\hline Kannus & 5 & 0.3 & 0.07 & \\
\hline
\end{tabular}

Table 4. Simulation information for 5 healthcare centers.

\begin{tabular}{|c|c|c|c|c|}
\hline $\mathbf{5}$ & No. Patient & LOS (hour).Max & LOS (hour).Ave & Resource Utilization(\%) \\
\hline Närpiö & 848 & 18 & 9 & 96 \\
\hline Luoto & 2391 & 38 & 20 & 96 \\
\hline Perho & 8 & 0.27 & 0.07 & 68 \\
\hline Perho & 0 & 0.13 & 0.05 & 15 \\
\hline Vaasa & 2412 & 38 & 20 & 97 \\
\hline
\end{tabular}




\section{DATA AND CHART ANALYZING}

In this section, various charts are presented for analyzing the simulation results.

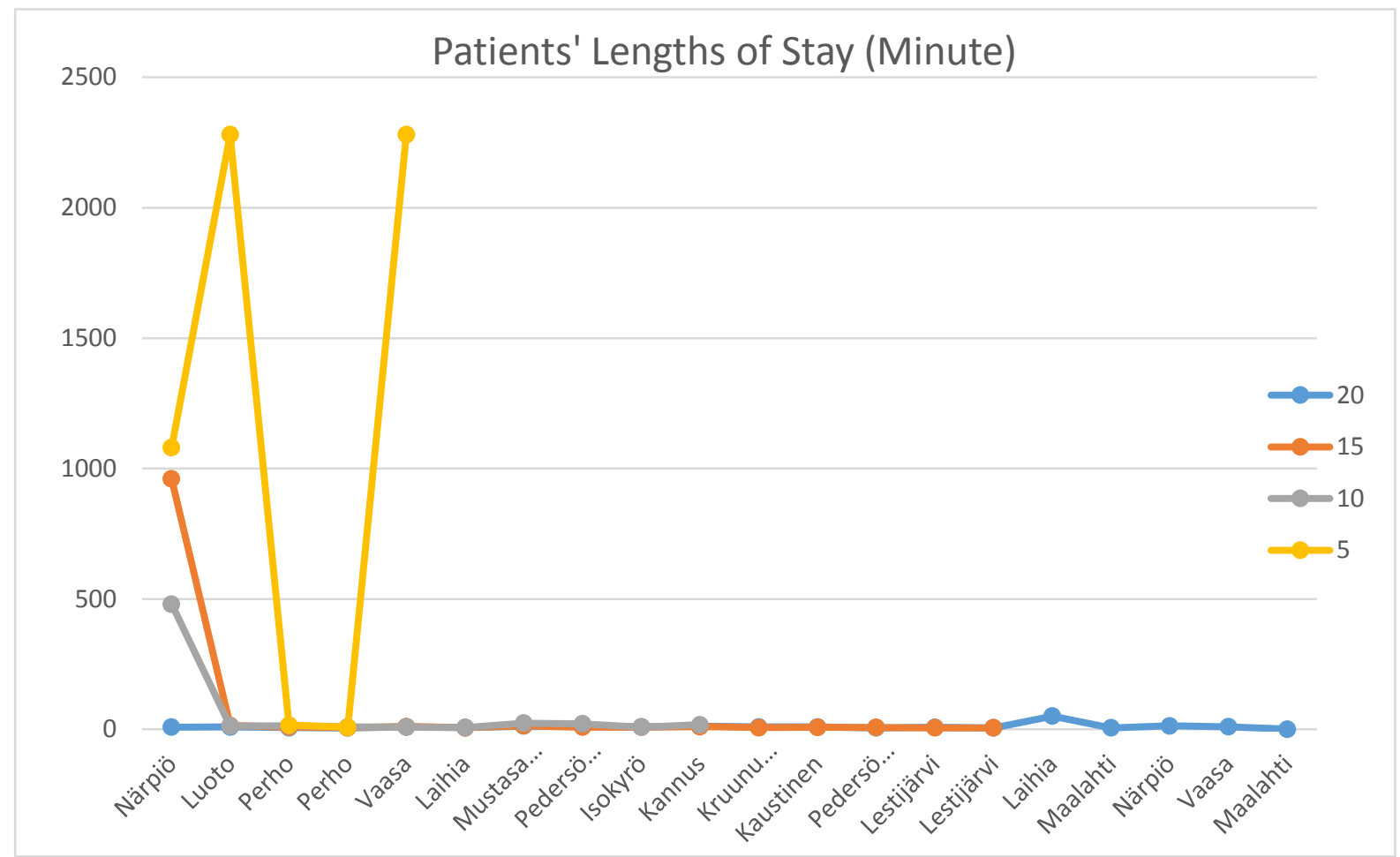

Figure 12. Maximum patient's lengths of stay per various number of healthcare centers. 


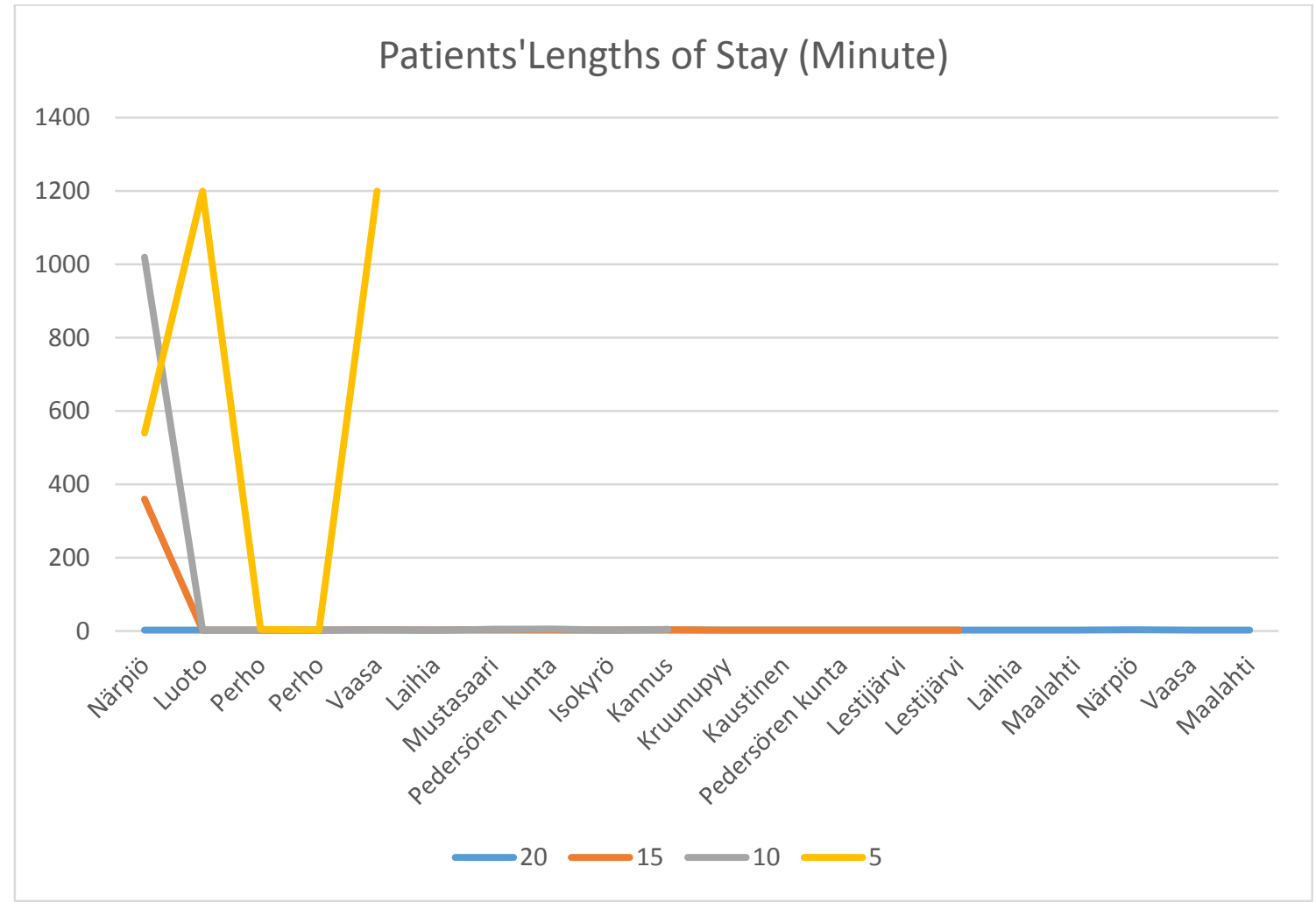

Figure 13. Average patient's lengths of stay per various number of healthcare centers. 


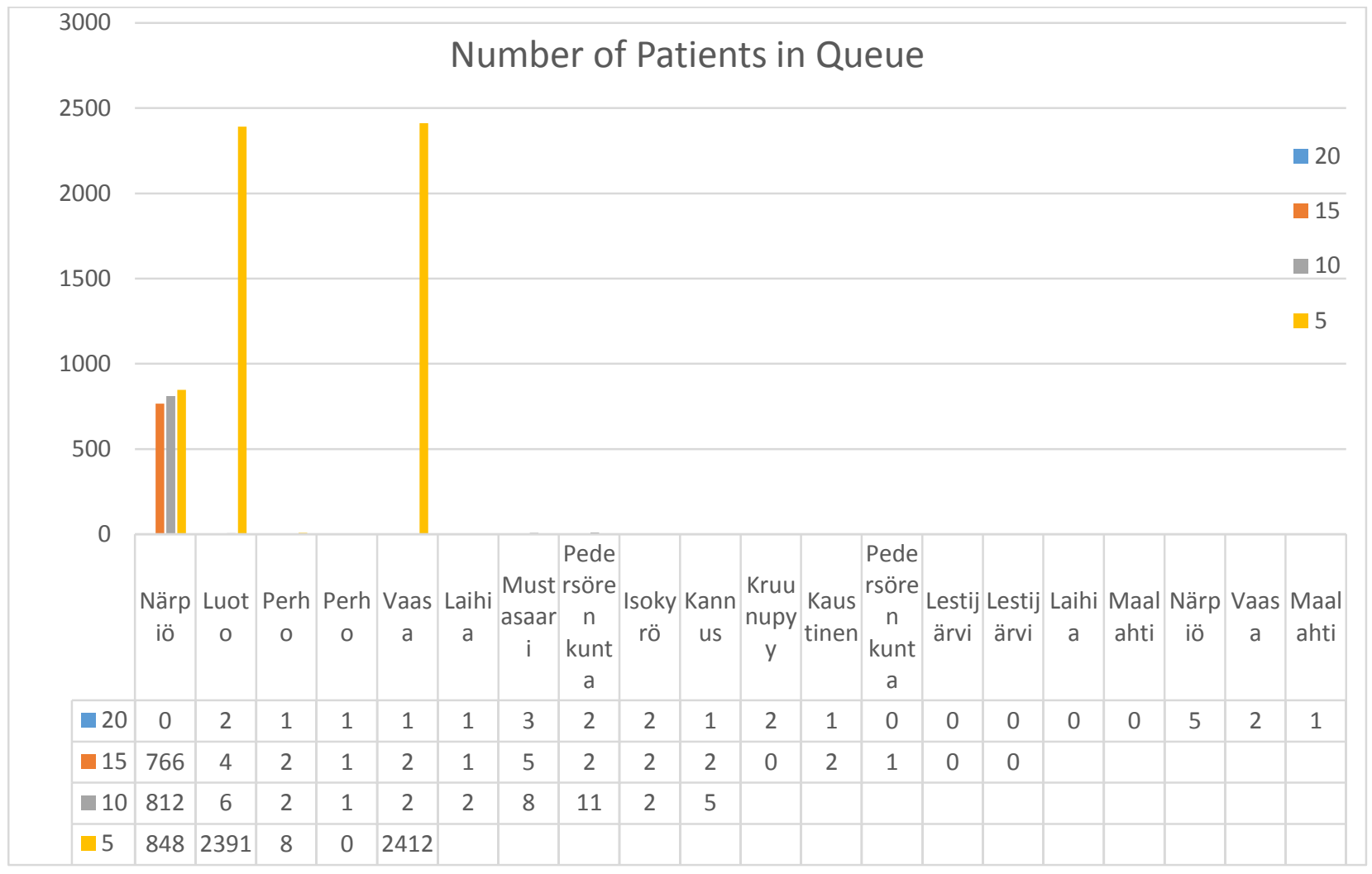

Figure 14. Number of Patients in Queue per each scenario.

Based on Figure 14, There is no remarkable change in patients number with 20,15,10 healthcare scenarios, except the Närpio site in which patients number increases dramatically with switching from 20 healthcare scenario to the others. 


\section{Resource Utilization}

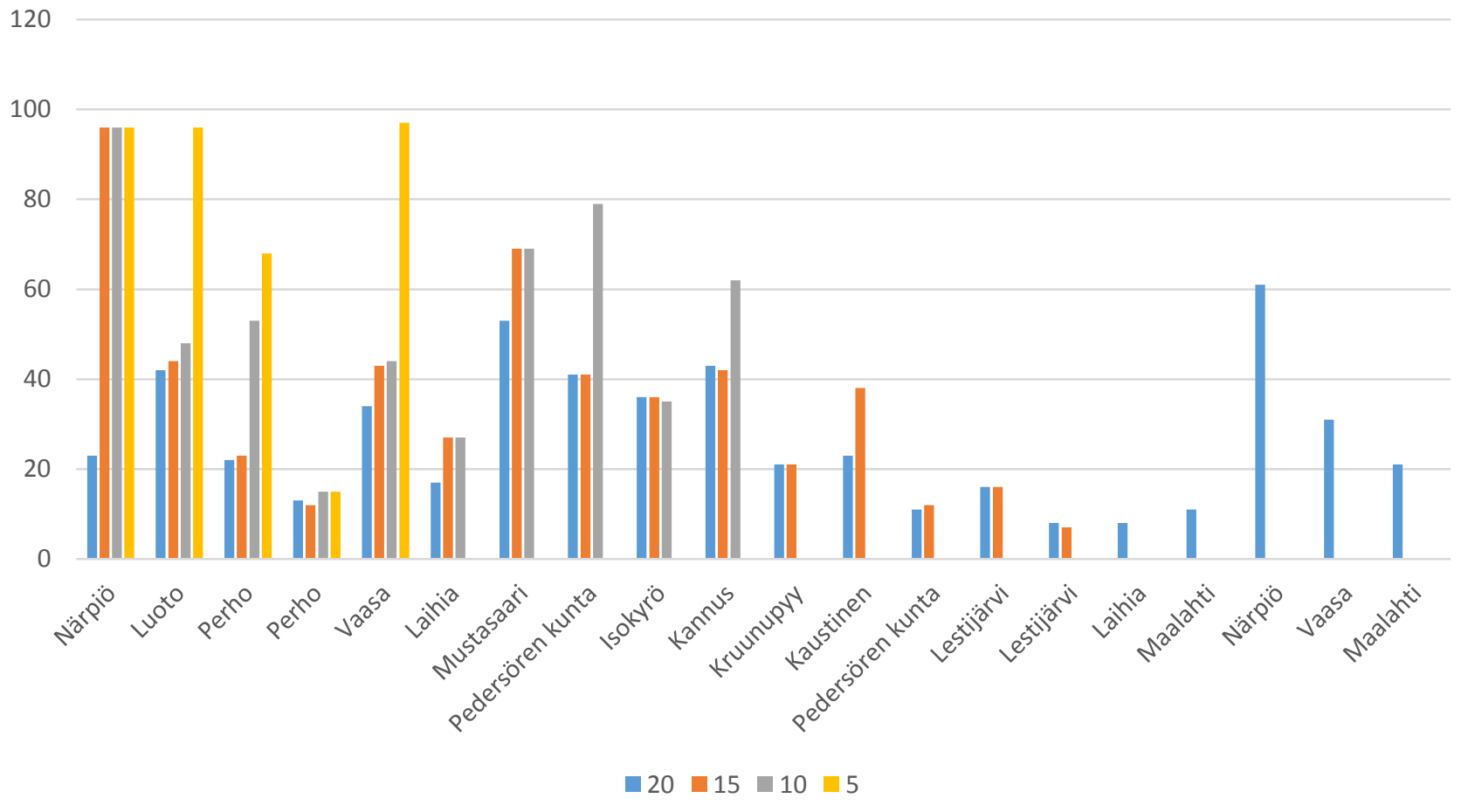

Figure 15. Resource Utilization per each scenario.

The purpose of modelling is to provide a tool for managers to assess different scenarios. With provided data and simulation result, different kind of analysis can be performed. Based on assumed scenarios, and presented figures, it can be concluded that three possible critical areas are Närpio, Luoto and Vaasa. Generally, from the KPI numbers can be seen there is slight difference between experiments with 20, 1510 healthcare centers, and KPI values suddenly increase with 5 healthcare center.

From Figure 15, it can be observed that resource utilization with 20 healthcare is under 60 percent for each site and resource utilization in first Närpio healthcare location is almost above 90 percent with 15, 10 and 5 healthcare scenarios. 
Also, in mentioned scenarios, number of doctors in each healthcare is fixed with two persons, and running simulation with lower or higher resource numbers can be considered as alternative scenarios. 


\section{RESULT AND DISCUSSION}

The share of healthcare systems in the economy of developed countries is between 8 to 15 percent which affirm the fact that it is one of the major country sectors. Healthcare organizations performance are examined closely by the society because they exist in turbulent political and social environment and this context impose the healthcare managers to make precise actions and decisions.

Furthermore, there are social trends in developed countries which changes the healthcare context and managers should consider them in the decisions; population shift, cost rising in healthcare systems, changing users expectations and rapid technology advancement. To resolve the healthcare problems, managers have utilized various methods and techniques. Operation research and management approaches also has been applied in this field; from quantitative and optimization methods to qualitative approaches.

Also, Modelling techniques such as agent-based simulation and discrete event simulation have been utilized for purpose of comprehending the major factors in healthcare system, factors interaction, and results derived from modification of healthcare system modelling.

Issues such as defining location of facilities, degree of resource units and service quality have been always a challenge for managers in decision making, particularly, regarding the facility location by considering the construction cost and huge amount of relocation cost. On the other hand, demand which has major role in any organization, cannot be precisely predicted and it has significant influences on facility operations.

In our research problem, healthcare managers have to decide regarding health centers location based on Pohjanmaan region population. In our method for resolving this issue, combination of Discrete Event (DE) and Agent-based (AB) simulation is applied. Patients are located on the map and they choose the nearest health centers to receive the medical services. In order to have more accurate modelling, geographical information system is also 
applied in modelling and population is located according to longitude and latitude obtained from official statistical information website of Finland.

In addition, what if analysis can be performed in simulation running. It is possible to change the number and location of health services and also resource units. Also, key performance indicators such resource utilization, number of patient in queue, patients waiting time are presented in simulation which can be utilized for measuring service quality of health centers.

By the presented simulation model, managers would be able to experiment alternatives without implementation in real life and by comparing the KPI, the most proper option can be chosen.

Complex agent based simulation modelling requires computer programming knowledge and the model can be developed in various approaches.

In addition, future researches can be conducted with the following areas:

- In this research, patients choose the nearest healthcare centers, while there are many factors which influence on the patient selection. Since various factors can be simulated also with agents and patient flow diagram, modelling can be performed with considering effect of "Word of mouth" or patients' feedback on healthcare selection. Also, adding priority for some healthcare centers can be considered in modelling.

- Another factor which can be considered is how seasonality affect the demand patterns, and consequently on service quality and efficiency.

- Various factors influence on possibility to become sick, for instance, individuals' age. Modelling would be more accurate if aging category can be added to patient flow diagram and related illness probability for each age group should be taken into account. 
- Moreover, modelling contagious diseases condition and interaction between agents combined with locating healthcare centers can be interesting topic, and results can be utilized and interpreted for dilemma situations. 


\section{LIST OF REFERENCES}

Alam SJ, M. R., Norling E. 2008. A model for HIV spread in a South African village. Estoril, Portugal: Multi-Agent Based Simulation IX: International Workshop MABS.

Alexopoulos, C., Goldsman, D., Fontanesi, J., Kopald, D., \& Wilson, J. R. 2008. Modeling patient arrivals in community clinics. Omega, 36(1): 33-43.

Balci, O. 1997. Verification validation and accreditation of simulation models. Paper presented at the Proceedings of the1997 Winter Simulation Conference, Atlanta, Georgia, USA.

Basole, R. C., Bodner, D. A., \& Rouse, W. B. 2013. Healthcare management through organizational simulation. Decision Support Systems, 55(2): 552-563.

Beliën, J., De Boeck, L., Colpaert, J., Devesse, S., \& Van den Bossche, F. 2013. Optimizing the facility location design of organ transplant centers. Decision Support Systems, 54(4): 1568-1579.

Bhattacharjee, P., \& Ray, P. K. 2014. Patient flow modelling and performance analysis of healthcare delivery processes in hospitals: A review and reflections. Computers \& Industrial Engineering, 78: 299-312.

Birge, J. R. 1997. State-of-the-Art-Survey-Stochastic Programming: Computation and Applications. INFORMS journal on computing, 9(2): 111-133.

Boloori Arabani, A., \& Farahani, R. Z. 2012. Facility location dynamics: An overview of classifications and applications. Computers \& Industrial Engineering, 62(1): 408420.

Bolus, N., George, R., Washington, J., Newcomer, B. 2009. PET/MRI: The blendedmodality choice of the future? Journal of Nuclear Medicine Technology: 63-71.

Brailsford, S., \& Vissers, J. 2011. OR in healthcare: A European perspective. European Journal of Operational Research, 212(2): 223-234.

Brandeau, M. L., Sainfort, F., \& Pierskalla, W. P. 2004. Operations research and health care: A handbook of methods and applications. USA: Springer-Verlag.

Bryce J, G. K., Jones G, Hazel E, Black RE, Victora CG. 2010. The Accelerated Child Survival and Development programme in west Africa: a retrospective evaluation. Lancet: $375-572$. 
Carrol.L. 2004. Clinical skills for nurses in medical assessment units. Nursing Standard, 18: $33-40$.

Chen, G., Daskin, M. S., Shen, Z. J., \& Uryasev, S. 2006. The a-reliable mean-excess regret model for stochastic facility location modeling. NAVAL RESEARCH LOGISTICS, 53(7): 617-626.

Chu, Y., You, F., Wassick, J. M., \& Agarwal, A. 2015. Simulation-based optimization framework for multi-echelon inventory systems under uncertainty. Computers \& Chemical Engineering, 73: 1-16.

CMS. 2010. National Health Expenditure Data: Centers for Medicare \& Medicaid Services.

Cochran, J. K., \& Roche, K. T. 2009. A multi-class queuing network analysis methodology for improving hospital emergency department performance. Computers \& Operations Research, 36(5): 1497-1512.

Côté, M. J. 1999. Patient flow and resource utilization in an outpatient clinic. SocioEconomic Planning Sciences, 33(3): 231-245.

Côté, M. J., \& Stein, W. E. 2007. A stochastic model for a visit to the doctor's office. Mathematical and Computer Modelling, 45(3-4): 309-323.

Daneshzand, F., \& Shoeleh, R. 2009. Multifacility location problem. Heidelberg: PhysicaVerlag.

De Bruin, A., van Rossum, A. C., Visser, M. C., \& Koole, G. M. 2007. Modeling the emergency cardiac in-patient flow: an application of queuing theory. Health Care Management Science, 10(2): 125-137.

Diaz-Banez, J. M., Mesa, J. A., \& Schobel, A. 2004. Continuous location of dimensional structures. European Journal of Operational Research, 152(1): 22-24.

Dokmeci, V. 1997. A quantitative model to plan regional health facility systems. Management Science, 24: 411-419.

Drezner, Z., \& Wesolowsky, G. O. 1991. Facility location when demand is time dependent. Naval Research Logistics (NRL), 38(5): 763-777.

Farahani, R., Drezner, Z., \& Asgari, N. 2009. Single facility location and relocation problem with time dependent weights and discrete planning horizon. Annals of Operations Research, 167(1): 353-368. 
Findlay, M., \& Grant, H. 2011. An application of discrete-event simulation to an outpatient healthcare clinic with batch arrivals. Paper presented at the Proceedings of the 2011 Winter Simulation Conference.

Funk, S., Vincent, A., \& Jansen, A. 2013. The talk of the town: modelling the spread of information and changes in behaviour, In Modeling the interplay between human behavior and the spread of infectious diseases: 93-102: Springer.

Garg, L., McClean, S., Meenan, B., \& Millard, P. 2010. A non-homogeneous discrete time Markov model for admission scheduling and resource planning in a cost or capacity constrained healthcare system. Health Care Management Science, 13(2): 155-169.

Ge, H., Gray, R., \& Nolan, J. 2015. Agricultural supply chain optimization and complexity: A comparison of analytic vs simulated solutions and policies. International Journal of Production Economics, 159: 208-220.

Gorunescu, F., McClean, S. I., \& Millard, P. H. 2002a. A queueing model for bedoccupancy management and planning of hospitals. Journal of the Operational Research Society, 53(1): 19-24.

Gorunescu, F., McClean, S. I., \& Millard, P. H. 2002b. Using a queueing model to help plan bed allocation in a department of geriatric medicine. Health Care Management Science, 5(4): 307-312.

Green, L. 2006. Queueing Analysis in Healthcare. In R. Hall (Ed.), Patient Flow: Reducing Delay in Healthcare Delivery, Vol. 91: 281-307: Springer US.

Green, L. V., \& Nguyen, V. 2001. Strategies for cutting hospital beds: the impact on patient service. Health Services Research, 36(2): 421-442.

Gunal, M. M. 2012. A guide for building hospital simulation models. $H S, 1(1)$ : 17-25.

Gunal, M. M., \& Pidd, M. 2006. Understanding accident and emergency department performance using simulation. Paper presented at the Proceedings of the 2006 Winter Simulation Conference, Monterey, CA.

Haifeng, X., Chaussalet, T. J., \& Millard, P. H. 2006. A Model-Based Approach to the Analysis of Patterns of Length of Stay in Institutional Long-Term Care. Information Technology in Biomedicine, IEEE Transactions on, 10(3): 512-518.

Hall, R., Belson, D., Murali, P., \& Dessouky, M. 2006. Modeling Patient Flows Through the Healthcare System. In R. Hall (Ed.), Patient Flow: Reducing Delay in Healthcare Delivery, Vol. 91: 1-44: Springer US. 
Harper, P. R., \& Shahani, A. K. 2002. Modelling for planning and management of bed capacities in hospitals. The Journal of the Operational Research Society, 53(1): 1118.

Harrison, G., Shafer, A., \& Mackay, M. 2005. Modelling Variability in Hospital Bed Occupancy. Health Care Management Science, 8(4): 325-334.

Holm, L. B., \& Dahl, F. A. 2010. Simulating the influence of a 45\% increase in patient volume on the emergency department of Akershus University hospital. Paper presented at the Proceedings of the 2010 Winter Simulation Conference.

Howe, J. 2009. Crowdsourcing: Why the Power of the Crowd Is Driving the Future of Business. New York: Crown Publishing Group.

Hulshof, P. J. H., Kortbeek, N., Boucherie, R. J., Hans, E. W., \& Bakker, P. J. M. 2012. Taxonomic classification of planning decisions in health care: a structured review of the state of the art in OR/MS. HS, 1(2): 129-175.

Jiang, L., \& Giachetti, R. 2008. A queueing network model to analyze the impact of parallelization of care on patient cycle time. Health Care Management Science, 11(3): 248-261.

Katsaliaki, K., \& Mustafee, N. 2011. Applications of simulation within the healthcare context. J Oper Res Soc, 62(8): 1431-1451.

Kisken, T. 2008. Hospitals are outsourcing radiology work: Ventura Country Star.

Koopmans, T. C., \& Beckmann, M. J. 1975. Assignment problems and the location of economic activities. Econometrica, 25(1): 53-76.

Korenromp E, K. R., Katz I, Katz I, Xueref S, Low-Beer D, et al. 2007. Operational research on HIV/AIDS, tuberculosis and malaria control in Global. Paper presented at the Proceedings of the 5th European conference on tropical medicine and international health, Amsterdam.

Lancioni, R. A. 2000. New Developments in Supply Chain Management for the Millennium. Industrial Marketing Management, 29(1): 1-6.

Lowery, J. C. 1996. Introduction to simulation in health care. In J. M. Charnes, D. J. Morrice, D. T. Brunner, \& J. J. Swain (Eds.), Proceedings of the 1996 Winter Simulation Conference: 78-84.

Macal, C., \& North, M. 2006. Tutorial on agent-based modeling and simulation part 2: how to model with agents,. Paper presented at the Proceedings of the Winter Simulation Conference. 
Mahar, S., Bretthauer, K. M., \& Salzarulo, P. A. 2011. Locating specialized service capacity in a multi-hospital network. European Journal of Operational Research, 212(3): 596-605.

Mao, L. 2014. Modeling triple-diffusions of infectious diseases, information, and preventive behaviors through a metropolitan social network and agent-based simulation. Applied Geography: 31-39.

Marshall, A., \& McClean, S. 2004. Using Coxian Phase-Type Distributions to Identify Patient Characteristics for Duration of Stay in Hospital. Health Care Management Science, 7(4): 285-289.

Maya Duque, P. A., Castro, M., Sörensen, K., \& Goos, P. 2015. Home care service planning. The case of Landelijke Thuiszorg. European Journal of Operational Research, 243(1): 292-301.

McClean, S. I., McAlea, B., \& Millard, P. H. 1998. Using a Markov reward model to estimate spend-down costs for a geriatric department. J Oper Res Soc, 49(10): 10211025.

McGlynn, E. A., Asch, S. M., Adams, J., Keesey, J., Hicks, J., DeCristofaro, A., \& Kerr, E. A. 2003. The quality of healthcare delivered to adults in the United States. The New England Journal of Medicine, 348(26): 2635-2645.

Mestre, A. M., Oliveira, M. D., \& Barbosa-Póvoa, A. P. 2015. Location-allocation approaches for hospital network planning under uncertainty. European Journal of Operational Research, 240(3): 791-806.

Miller, T. C., Friesz, T. L., Tobin, R. L., \& Kwon, C. 2007. Reaction function based dynamic location modeling in Stackelberg-Nash-Cournot competition. Networks and Spatial Economics, 7(1): 77-97.

Min, H., \& Melachrinoudis, E. 1999. The relocation of a hybrid manufacturing/distribution facility from supply chain perspectives: a case study. Omega, 27(1): 75-85.

Mitropoulos, P., Mitropoulos, I., Giannikos, I., Sissouras, A. 2006. A biobjective model for the locational planning of hospitals and health centers. Health Care Management Science, 9(2): 171-179.

Mortazavi, A., Arshadi Khamseh, A., \& Azimi, P. 2015. Designing of an intelligent selfadaptive model for supply chain ordering management system. Engineering Applications of Artificial Intelligence, 37: 207-220.

O'Kelly, M. E. 1987. A quadratic integer program for the location of interacting hub facilities. European Journal of Operational Research, 32(3): 393-404. 
Oddoye, J. P., Jones, D. F., Tamiz, M., \& Schmidt, P. 2009. Combining simulation and goal programming for healthcare planning in a medical assessment unit. European Journal of Operational Research, 193(1): 250-261.

Oliveira, M., \& Bevan, G. 2006. Modelling the redistribution of hospital supply to achieve equity taking account of patient's behavior. Health Care Management Science, 9(1): 19-30.

Olsen, L., Aisner, D., \& McGinnis, M. J. 2007. The Learning Healthcare System. Washington D.C: National Academies Press.

Owen, S. H., \& Daskin, M. S. 1998. Strategic facility location: A review. European Journal of Operational Research, 111(3): 423-447.

Pidd, M. 2003. Tools for thinking: modelling in management science, 2 nd edition.: Chichester: John Wiley \& Sons.

Porter, M. 1990. The competitive advantage of nations. New York: Free Press.

Rais, A., \& Viana, A. 2011. Operations Research in Healthcare: a survey. International Transactions in Operational Research, 18(1): 1-31.

ReVelle, C. S., Eiselt, H. A., \& Daskin, M. S. 2008. A bibliography for some fundamental problem categories in discrete location science. European Journal of Operational Research, 184(3): 817-848.

ReVelle, C. S., \& Swain, R. W. 1970. Central facilities location. Geographical Analysis, 2(1): $30-42$.

Robinson.S. 2004. Simulation: The Practice of Model Development and Use: John Wiley and Sons Ltd.

Ross, G., \& Soland, R. 1980. A multicriteria approach to the location of public facilities. European Journal of Operational Research, 4(21): 307.

Ross, S. M. 2009. Stochastic processes (2nd ed.). New Delhi: John Wiley and Sons.

Rouse, W. B. 2000. Managing complexity: disease control as a complex adaptive system. Information Knowledge and Systems Management, 2(2): 143-165.

Rouse, W. B., \& Cortese, D. A. 2010. Engineering the System of Healthcare Delivery. Amesterdam: IOS Press.

Royston, G. 2009. One hundred years of operational research in health. Journal of the Operational Research Society: 169-179. 
Royston, G. 2011. Meeting global health challenges through operational research and management science. World Health Organization.Bulletin of thr World Health Organization: Vol.89, no.89, p. 683-688.

Royston.G. 2007. Modelling and simulation in health-potential achievement and challenge. Presentation for MASHnet launch.

Saaty, T. 1980. The analytic hierarchy process. New York: McGraw Hill.

Sahin, G., \& Sural, H. 2007. A review of hierarchical facility location models. Comput. Oper. Res., 34(8): 2310-2331.

Surowiecki, J. 2005. The Wisdom of Crowds. New York: Anchor.

Taboada, M., Cabrera, E., Iglesias, M. L., Epelde, F., \& Luque, E. 2011. An Agent-Based Decision Support System for Hospitals Emergency. Procedia Computer Science: 1870-1879.

Toregas, C., Swain, R., ReVelle, C., \& Bergman, L. 1971. The location of emergency service facilities. Operations Research, 19(6): 1363-1373.

Unknown. 2006. National Academies: engineering the health care system. Washington, DC.

Verter, V., \& LaPierre, S. 2002. Location of preventative health care facilities. Annals of Operations Research(110): 123-132.

Vriend, N. J. 2000. An illustration of the essential difference between individual and social learning, and its consequences for computational analyses. Journal of Economic Dynamics and Control, 24(1): 1-19.

Waleed Abo-Hamad, A. A. 2013. Simulation-based framework to improve patient experience in an emergency department. European Journal of Operational Research: $154-166$.

Walshe, K., \& Smith, J. 2011. Healthcare Management (2nd Edition): McGraw-Hill Education.

Wesolowsky, G. O. 1973. Dynamic facility location. Management Science, 19(11): 12411248.

Wesolowsky, G. O., \& Truscott, W. G. 1975. The multi-period location-allocation problem with relocation of facilities. Management Science, 22(1): 57-65. 
Worthington, D. 2009. Reflections on queue modelling from the last 50 years. J Oper Res Soc, 60(S1): S83-S92.

Wu, C.-R., Lin, C.-T., \& Chen, H.-C. 2007. Optimal selection of location for Taiwanese hospitals to ensure a competitive advantage by using the analytic hierarchy process and sensitivity analysis. Building and Environment, 42(3): 1431-1444.

Xie, H., Chaussalet, T. J., \& Millard, P. H. 2005. A continuous time Markov model for the length of stay of elderly people in institutional long-term care. Journal of the Royal Statistical Society: Series A (Statistics in Society), 168(1): 51-61.

Yeon, N., Lee, T., \& Jang, H. 2010. Outpatient appointment scheduling with miltidoctor sharing resources. Paper presented at the Proceedings of the 2010 Winter Simulation Conference.

Zhang, Y., Puterman, M. L., Nelson, M., \& Atkins, D. 2012. A simulation optimization approach to long-term care capacity planning. Operations Research, 60(2): 249-261. 